NBER WORKING PAPER SERIES

\title{
THE PERMANENT INCOME HYPO'THESIS AND CONSUMPTION DURABILITY: ANALYSIS \\ BASED ON JAPANESE PANEL DATA
}

Fumio Hayashi

Working Paper No. 1305

NATIONAI BUREAU OF ECONOMIC RESEARCH

1050 Massachusetts Avenue

Cambridge, MA 02138

March 1984

I am grateful for comments and suggestions received during workshops at Osaka, Nagoya, Nothwestern and MIP. AIl the computations were done at the Economic Planning Agency of the Japanese government. The research reported here is part of the NBER's research program in Economic Fluctuations. Any opinions expressed are those of the author and not those of the National Bureau of sconomic Research. 
NBER Working Paper \#1305

March 1984

The Permanent Income Hypothesis and Consunption Duraility: Analys is based on Japanese Panel Data

\title{
ABSTRACT
}

The permanent income hypothesis is tested on a four-quarter panel of about two thousand Japanese households for ten commodity groups. Consumption is a distributed lag function of expenditures, and the utility function is additively separable in time. Durability is defined as the persistence of the distributed lag. The permanent income hypothesis implies that, for each commodity group, expected change in expenditures is correlated neither with past expenditure changes on other commodities nor with expected change in disposable income, if its own lags are controlled for. The main results are the following: (1) durability is substantial even for food and services, (2) the permanent income hypothesis applies to almost all (probably more than ninety percent) of the population, and (3) the habit persistence hypothesis is rejected in favor of the permanent income hypothesis.

\author{
Fumio Hayashi \\ Institute of Socio-Economic \\ Planning \\ University of Tsukuba \\ Sakura, Ibaraki 305, JAPAN
}




\section{INTRODUCTION and SUMMARY}

The empirical validity of the permanent income hypothesis ${ }^{1}$ is a longstanding issue that has been debated for nearly three decades. At the heart of the debate is the question of whether or not consumption is "too sensitive" to income fluctuations. Its operational meaning was not given until the publication of Hall's (1978) paper which has shown that the permanent income hypothesis implies the marginal utility of consumption is a martingale. Since then quite a few papers have studied the issue of the excess sensitivity of consumption. 2 Many of them have also tried to estimate the fraction of households in the population that follow the permanent income hypothesis rather than simply keep track of disposable income. Although those papers differ in terms of the component of consumption (food, nondurables, services, or durables) and the kind of data set (time-series, cross-section, or panel) that they use, there seems to be a consensus that the permanent income hypothesis applies to 70 to 100 percent of the population.

As impressive as it is, the empirical literature has failed to address two important issues. First, not much attention has been paid to the distinction between consumption and expenditures. Total expenditures are dichotomized into perishables (nondurables and services) and durables. Since the permanent income hypothesis is a theory about the flow of consumption, the empirical literature has either looked at perishables alone or singled out durables for special treatment. However, it is not entirely clear that most commodities labeled as nondurables and services are perishable so that consumption and expenditures can be equated. A good example is dental services. ${ }^{3}$ People go to a dentist not because they enjoy the treatment but because they hope that their teeth will be in good shape for some time to come. So dental services are essentially durable expenditures. Another 
example is a pleasure trip. It is obviously physically perishable, but it might have a lasting psychological effect on preferences as people derive utility from the memory of a trip. If so, recreational expenditures should be treated as if they are durable expenditures. Second, all the empirical evidence that has been put forth to support the permanent income hypothesis with a possible exception of Hall and Mishkin (1982) - seems to be also consistent with the habit persistence hypothesis (Brown [1952]) that current consumption is determined by the history of past consumption and current income. If households are forward-looking as is postulated by the permanent income hypothesis, the distinction between permanent and temporary tax changes is a crucial one. That is not the case if households are backward-looking as is postulated by the habit peristence hypothesis. So it is important from the viewpoint of stabilization policies to discriminate the permanent income hypothesis from the habit persistence hypothesis.

This study attempts to address the above two issues as well as obtain a sharper estimate of the fraction of the population that is explained by the permanent income hypothesis. It uses a four-quarter panel of about two thousand households in Japan for ten commodity groups. The unique feature of this data set is that it has information on expectations about expenditures and income. The most striking fact revealed by the data set is that an increase in expenditures tends to be followed by a decrease, i.e., the firstorder autocorrelation in expenditure changes are negative. This seems to be inconsistent with the permanent income hypothesis, if consumption is well proxied by expenditures.

The theoretical model in this study makes an explicit distinction between consumption and expenditures by postulating that consumption is a distributed lag function of current and past expenditures. Otherwise the model is a 
standard one: the household's objective function is additively separable in time, and the lifetime budget constraint is the only constraint faced by the household. It is shown, under a certain set of restrictions on the household's preferences, that consumption follows a martingale. This means that change in expenditures on any single commodity group depends only on its own past changes and unforecastable events, namely it is an univariate autoregression. If the commodity is perishable both physically and psychologically (so that expenditures affect the utility only for the current period), there should be no lagged expenditure changes in the univariate autoregression; if the commodity is highly durable, lagged expenditure changes should have coefficients close to unity in absolute value. Thus the theoretical model provides a unified treatment of commodities with differing degrees of durability. This is useful from the viewpoint of macroeconomic stabilization policies, because the implied equation is stated in expenditures, not in consumption, and expenditures are components of aggregate demand.

There are three major empirical findings that energe from the estimation of the model. First, lagged expenditure changes are significant even for food and services, which suggests that they are not really perishables. Second, if its own lags are controlled for, current change in expenditures is not sensitive to the forecastable part of current income change. That is to say, the martingale hypothesis is valid in consumption, but not in expenditures. Third, current change in expenditures is sensitive to the unforecastable part of current income change. It is hard to reconcile this finding with the habit persistence hypothesis which assumes households are backward-looking.

The plan of the paper is as follows. Section 2 describes the data set and takes a look at sample means, standard deviations, and correlations of relevant variables. Section 3 presents the theoretical model and derives the 
equation stated in expenditures. A few econometric issues concerning the estimation of the equation on a short panel are discussed in Section 4. Parameter estimates are presented in Section 5. The paper concludes with a few remarks in Section 6.

\section{DATA DESCRIPTION}

The data set for the present study is obtained from the 1982 Survey of Family Consumption compiled by the Economic Planning Agency of the Japanese government. This is an interview panel survey in which families reported to visiting interviewers every three months over a four-quarter period (1981:Q21982:Q1). More specifically, respondents are asked at the end of each quarter to provide the following information: ( $i$ ) expenditures on ten different and mutually exclusive commodity groups for the quarter, 4 (ii) "normal" income net of taxes and social security contributions, (iii) "temporary" income net of taxes and social security contributions, (iv) the respondent's expectations (at the end of each quarter) of all the variables in the above three items for the following quarter, and ( $v$ ) family characteristics (occupation, family size, age of the head, and housing tenure). 5 "Normal" income is equal to after-tax labor income net of bonuses. "Temporary" income is the sum of property income, bonuses, severence pay, and tax returns at the end of a calender year. The survey does not cover one-person households. Although this is not a diary survey, interviewers actually visited the households every quarter and the respondents filled out the questionaire in the presence of the interviewer. There are practically no attritions: for any quarter at least 99.5 percent of the surveyed 5,837 households responded. Information about food, for example, is elicited by the question: "How much did your family 
spend on food for the last three months?" and "How much do you expect your family will spend on food for the next three months?"

Of the original sample, only "workers' households," namely households whose head is on a payroll, are selected. They are about 58 percent of the original sample. Farmers and households with unincorporated business are excluded from the sample as their income pattern is distinctly different from that of workers' households who receive semiannual bonuses. If the age of the head either increases by more than a year or decreases, the household is deleted in forming the pane1. It became necessary to delete the sample from the entire Tokyo prefecture and other parts of the country, because I could not form a four-quarter panel due to some coding problem. At this stage the sample size became 2,518. From this, households which did not provide relevant information ( 455 cases) and then households which changed their housing tenure (from a homeowner to a nonhomeowner or from a nonhomeowner to a homeowner) (46 cases) are deleted. ${ }^{6}$ This left a sample of 2,017 cases. For this sample I examined the empirical distribution and decided to remove seven cases which reported extreme values. ${ }^{7}$ The sample size become 2,010.

The variables used in the analysis are as follows (for a quick reference see Table 8):

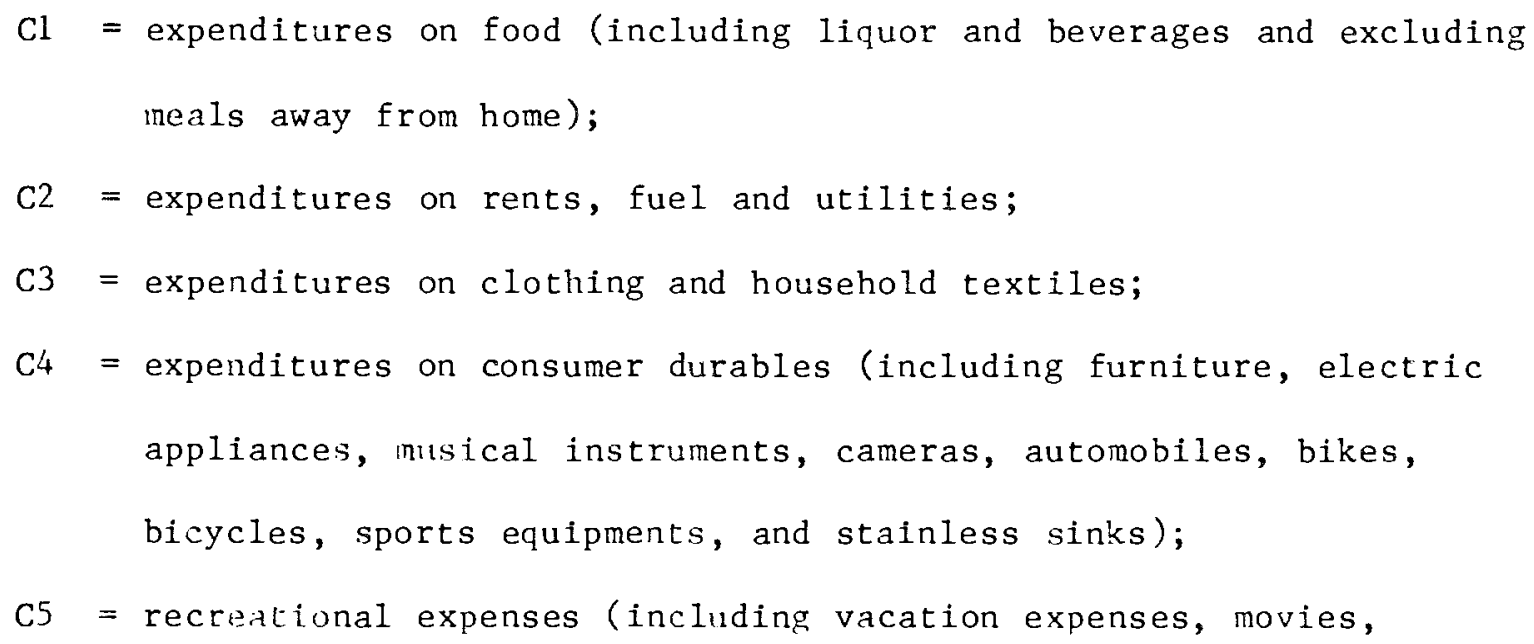




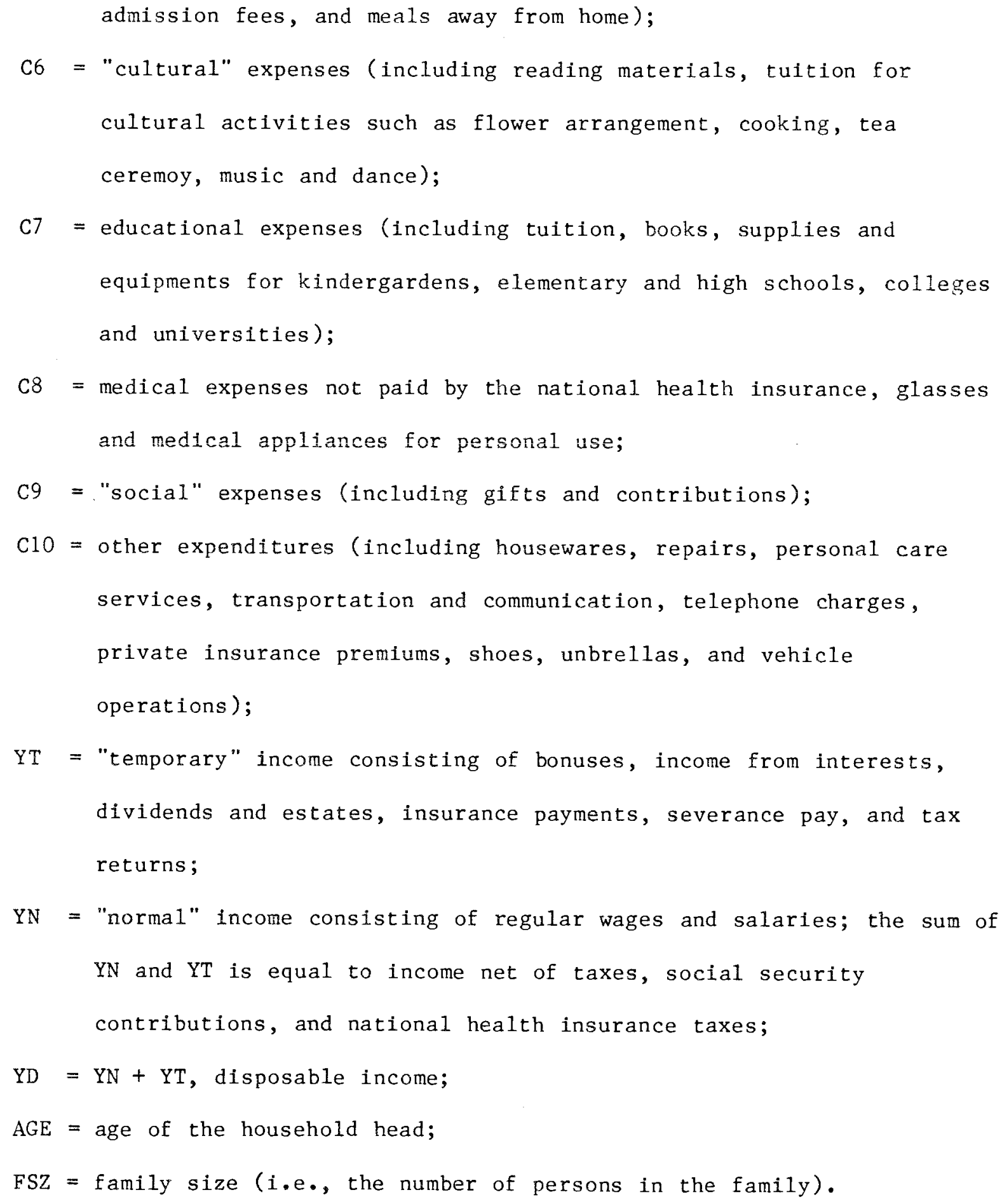

I use subscripts to denote the quarter. For example, $\mathrm{Cl}_{1}$ is food expenditures in the first quarter of the pane1 (1981:Q2), and $\mathrm{Cl}_{4}$ is food expenditures in quarter four (1982:Q1). Consumption and income variables are all deflated by the corresponding components of the CPI (consumer price index). Variables C9, 
YN and YT are deflated by the overall CPI. A weighted average of the transportation, communication, and miscellaneous components of the CPI is used to deflate $\mathrm{ClO}$. Since prices were very stable during the period covered by the panel (the inflation rate during the period was 2.8 percent), the choice of the deflator is imnaterial. Panel A of Table 1 displays the means and standard deviations of the relevant variables.

In the subsequent analysis, I will use consumption expenditures and income adjusted for family size. This adjustment is done by dividing the variable by the number of equivalent adults which is estimated by regressing the $\log$ of the variable on family size dummies. The regressions are run on pooled data. Table 2 reports the results of expenditures and income regressions on pooled data. If the regressions were run for each quarter, the intercept term would pick up economy-wide shocks and the residual would be purged of any seasonal and macroeconomic fluctuations. The antilog of the residual from the pooled regression is taken to be the value of the variable adjusted for family size. If the (unadjusted) value is zero, its adjusted value is set at zero also. Put more formally, the family size-adjusted value of $X_{t}$ is the ratio of the unadjusted value fo $X_{t}$ diviled by $f_{X}\left(\right.$ FSz $\left._{t}\right)$, where $f_{X}$ is a function defined in Table 2 that converts family size in period $t, F S z_{t}$, into the number of equivalent adults specific to $\mathrm{X}(\mathrm{X}=\mathrm{Cl}, \mathrm{C2}, \ldots, \mathrm{Cl}) \mathrm{.}^{8}$ For example, $\mathrm{f}_{\mathrm{Cl}}(2)=1.0, \mathrm{f}_{\mathrm{Cl}}(3)=\exp (.232), \mathrm{f}_{\mathrm{Cl}}(4)=\exp (.326), \mathrm{f}_{\mathrm{Cl}}(5)=$ $\exp (.423)$, and so forth. These numbers cone from the estinated coefficients of the family size dummies reported in Table 2 . The number of equivalent adults is normalized to unity for two-person families. (Note that the sample does not include one-person households.) The means and standard deviations of the family size-adjusted variables thus obtained are displayed in Panel $B$ of Table 1 . Since the $R^{2}$ for the regressions reported in Table 2 is uniformly 
very low except for food expenditures and since very few households changed its family size during the period of the survey, this particular way of adjusting for family size should not (and in fact did not) influence the results to be reported in this paper in any important way.

The present data set contains information on expectations held by households. Since the period of the survey is from 1981:Q2 to 1982:Q1, reported expectations refer to the period of 1981:Q3 to 1982:Q2. I wil1 put subscript "e" to denote expected values; for example, $\mathrm{Cl}_{t}^{\mathrm{e}}$ denotes the household's expectation, formed at the end of period $t-1$, of $C \bar{l}$ in period $t$ $(t=2,3,4,5$, or $t=1981: Q 3$ to $1982: Q 2$.$) . Exactly the same procedure for$ family size adjustment is used for expected values of expenditures. It is assumed that households can correctly foresee their family size one quarter ahead, so that actual family size is used to make family size adjustment on expected values. To be more precise, the family size-adjusted value of $x_{t}^{e}$ is the unadjusted value of $X_{t}^{e}$ divided by $f_{X}\left(F S Z_{t}\right)$, where $f_{X}$ is the function that translates family size in period $t, F S z_{t}$, into the number of equivalent adults specific to $X(X=C 1, C 2, \ldots, C l 0 ; t=2,3,4,5)$. Since there is no information on $\mathrm{FSZ}_{5}$ in the present four-quarter panel, it is assumed that $\mathrm{FSZ}_{5}$ is equal to $\mathrm{FSZ}_{4}$ - I also assume that each relevant component of the CPI is correctly foreseen by households one quarter ahead, so that actual values of the relevant deflators are used to convert expected values of expenditures and two components of income into real terms.

The theory to be presented in the next section is stated in terms of changes in expenditures. Theoretical considerations apart, it is a good idea to work with changes since levels of expenditures are likely to have household specific components that are time invariant. Table 3 displays the means and standard deviations of changes in the ten (family size-adjusted) commodity 
groups and in the two (Eamily size-unadjusted) components of income. As expected, the most volatile commodity group is durables. Both the level and the change of durables goods expenditures have a high standard deviation. This is a consequence of the lumpiness of durable purchases. In fact, in any given quarter, over forty percent of the sample reported zero expenditures on durables.

A quite surprising fact is revealed if one examines the autocorrelation structure of changes which is reported in Table 4. The first-order autocorrelation is uniformly negative and large in absolute value, even for changes in food expenditures. It is not surprising that changes in durable expenditures are negatively autocorrelated because of the lumpiness of durable purchases. However, the fact that an increase in food expenditures tends to be followed by a decrease is unsettling, because one would expect households to smooth out consumption over time. In fact, Hall's (1978) permanent income hypothesis implies that changes in consumption are serially uncorrelated as the level of consumption is changed only when the consumer receives new information. That implication is strongly rejected by the present data.

Several explanation are conceivable for the strong negative autocorrelation. First, as Table 1 shows, expenditures have seasonality. In particular, expenditures go up in the fourth quarter and come back down in the first quarter of the following year. If the effect of seasonality is multiplicative rather than additive, then the autocorrelation coefficients in changes will be negative. I performed seasonal adjustment on expenditures and income to re-calculate the sample autocorrelations. ${ }^{9}$ This is reported in the right half of table 4. Although the size of autocorrelation involving the fourth quarter is now smaller in general, the strong negative autocorrelation still remains. 
The second explanation is measurement error. Survey data on expenditures are necessarily subject to measurement error. If the levels of expenditures are measured with error, changes in measured expenditures will have a moving average term which induces negative autocorrelation. The third explanation is that preferences are subject to taste shocks. This also introduces a moving average term in expenditure changes. ${ }^{10}$ Both measurement error and taste shocks may explain some of the negative correlation in expenditure changes. However, I do not think they are the main factor. For one thing, in a separate study that uses monthly diary survey data, it is found that monthily change in food expenditures are strongly negatively correlated. ${ }^{11}$ Since it is reasonable to assume measurement error in diary surveys is small, something other than measurement error must be responsible for the negative autocorrelation. Another reason that measurement error and taste shocks are unimportant is provided by the vector autoregression (VAR) model estimated in Table 5.12 Suppose that change in expenditures is the sum of new information (forecast errors) and a moving average of measurement error and taste shocks. It is plausible that measurement error and taste shocks are uncorrelated with income changes. It is also plausible that income changes are correlated with forecast errors. Then if current expenditure change is regressed on lagged expenditure changes and lagged income changes, both lagged expenditure changes and lagged income changes should be significant. The results in Panel A of Table 5, on the contrary, say that only lagged expenditure changes are significant at the $1 \%$ significance level except for $C 9$ (social expenses). The significant contemporaneous correlation between expenditure changes and income changes reported in Panel B of Table 5 implies that expenditure changes are not dominanted by measurement error and taste shocks.

It is the basic theme of this paper that the main factor that lies behind 
the significant negative autocorrelation in expenditure changes is the durability of commodities. The next section sets up an optimization model that is capable of explaining the negative autocrelation.

\section{THEORY}

As is made clear in the previous section, the standard permanent income hypothesis (Hall [1978]) is inconsistent with the data. Here I present a modified version of the standard theory. The key feature will be the durability of commodities. Consider a household whose intertemporal decision problem is to maximize

$$
E_{t}\left[\sum_{k=0}^{T} u\left(\bar{C}_{t+k}\right) \delta^{k}\right]
$$

subject to the budget constraint

$$
\sum_{k=0}^{T}\left[\prod_{v=0}^{k}\left(1+R_{t+v-1}\right)^{-1}\left(Y_{t+k}-p_{t+k}^{\prime} C_{t+k}\right)\right]+A_{t}=0
$$

where $E_{t}$ is the expectation operator associated with the subjective probability distribution (assumed by the household) of future variables that are uncertain to the household, $\delta$ is the rate of subjective time preference, $R$ is the nominal interest rate, $T$ is the length of the remaining life, $C$ is a vector of real expenditures on $n$ commodity groups, $p$ is the associated price vector of dimension $n, \bar{C}$ is a vector of consumption of the $n$ commodities, $u(\cdot)$ is the instantaneous utility function, $Y$ is after-tax nominal labor inocme, and $A_{t}$ is nominal nonhuman wealth (assets) at the beginning of period t. 13 Note that a distinction is made between consumption $\vec{C}$ and expenditures 
C. The $j$-th component of $\bar{C}_{t}$, namely $\bar{C}_{j t}$, is linked to the $j$-th component of $c_{t}$ by

$$
\bar{C}_{j t}=\sum_{k=0}^{M}\left(\rho_{j k} C_{j, t-k}\right) \quad(j=1,2, \ldots, n)
$$

That is, current consumption is a distributed lag function of current and past expenditures. This is a generalization of the usual formula for durable goods where $\bar{C}_{j t}$ is service flows from the stock of durables and the distributed lag coefficients $\rho_{j k}(k=0,1,2, \ldots)$ are of the Koyck type.

The first-order condition for this household's optimization problem is:

(3.4) $\quad E_{t}\left\{\sum_{k=0}^{M}\left[\delta^{k} \frac{\partial u\left(\bar{C}_{t+k}\right)}{\partial \bar{C}_{j, t+k}} \rho_{j k}\right]\right\}=E_{t}\left\{\left(1+r_{j, t+1}\right) \delta \sum_{k=0}^{M}\left[\delta^{k} \frac{\partial u\left(\bar{C}_{t+k+1}\right)}{\partial \bar{C}_{j, t+k+1}} \rho_{j k}\right]\right\}$

where $r_{j, t+1}$ is the real rate of interest on commodity $j, i \cdot e ., 1+r_{j, t+1}=$ $\left(1+R_{t}\right) p_{j t} / p_{j, t+1}$. The right hand side of this equation is the marginal cost of foregoing one unit of expenditures on the $j$-th commodity. This involves a summation from 0 to $M$ because a change in current expenditures influences current and future consumption for M periods. The left hand side is the marginal benefit of increasing $1+r_{j, t+1}$ units of expenditures on commodity $j$ in the next period. This also involves a summation from 0 to $M$ for the same reason. In Appendix A it is shown that: Under (3.4),

$$
E_{t}\left\{\left[\left(1+r_{j, t+1}\right) \delta \frac{\partial u\left(\bar{C}_{t+1}\right)}{\partial \bar{C}_{j, t+1}}\right] /\left[\frac{\partial u\left(\bar{c}_{t}\right)}{\partial \bar{C}_{j t}}\right]\right\}=1 \quad(j=1,2, \ldots, n)
$$

holds approximately if $M$ (the length of the distributed lag) is small relative to $T$ (the length of remaining life), and holds exactly if (as is usually the case for durables) $\rho_{j k}$ is geometrically declining in $k$ and $r_{j, t+1}$ is known in 
$t$ and $r_{j, t+1}=r_{j, t+2}$.

Equation (3.5) can be made tractable under two alternative assumptions. First, assume that the instantaneous utility function $\mathbf{u}(\cdot)$ takes the following form:

$$
u\left(\bar{C}_{t}\right)=-g_{1} \exp \left(-\mu_{1} \bar{C}_{1 t}\right)-\ldots-g_{n} \exp \left(-\mu_{n} \bar{C}_{n t}\right)
$$

Rewrite (3.5) as

$$
\left(1+r_{j, t+1}\right) \delta\left[\frac{\partial u\left(\bar{c}_{t+1}\right)}{\partial \bar{C}_{j, t+1}}\right] /\left[\frac{\partial u\left(\bar{c}_{t}\right)}{\partial \bar{C}_{j t}}\right]=1-e_{j, t+1},
$$

where $e_{j, t+1}$ is the difference between the right hand side of (3.5) and the right hand side of ( 3.7$)$, that is, $e_{j, t+l}$ is the forecast error of the right hand side of (3.7). Take the $\log$ of both sides of (3.7) and use the approximation that $\ln (1+x) \simeq x$ to obtain

$$
\ln \left(1+r_{j, t+1}\right)+\ln (\delta)+\ln \left[\frac{\partial u\left(\bar{C}_{t+1}\right)}{\partial \bar{C}_{j, t+1}}\right]-\ln \left[\frac{\partial u\left(\bar{C}_{t}\right)}{\partial \bar{C}_{j t}}\right]=-e_{j, t+1} \cdot
$$

Now use (3.6) on (3.8) to obtain

$$
\bar{c}_{j, t+1}-\bar{c}_{j t}=d_{j t}+e_{j, t+1} \quad(j=1,2, \ldots, n)
$$

where

$$
d_{j t}=\mu_{j}^{-1}\left[\ln \left(1+r_{j, t+1}\right)+\ln (\delta)\right]
$$

Another way to make (3.5) tractable is to assume that the instantaneous 
utility funciton $u(\cdot)$ is quadratic:

$(3.11)$

$$
u\left(\bar{C}_{t}\right)=a^{\prime} \bar{C}_{t}-(1 / 2) \bar{C}_{t}^{\prime} B \bar{C}_{t}
$$

and that

$$
\left(1+r_{j, t+1}\right) \delta=1
$$

It then is easy to show that (3.5) reduces to (3.9) with $\mathrm{d}_{j t}=0$. This is a multi-commodity version of of Hall's (1978) martingale hypothesis. Under either assumption about the instantaneous utility function, consumption on commodity $j$ is unrelated to lagged consumption on other commodities. Note that this result is obtained under the assumption which does not assume intratemporal separability among commodities. 14

The foregoing discussion has ignored two issues, namely family size and seasonality. I will incorporate them into the model in the following fashion. Let $f_{j t}$ be the commodity-specific number of equivalent adults in period $t$. I will use lower case letters $c_{j t}$ and $\bar{c}_{j t}$ to represent expenditure and consumption on commodity $j$ in period $t$ expressed in equivalent adult per capita, i.e.,

$$
c_{j t}=c_{j t} / f_{j t} \text { and } \bar{c}_{j t}=\bar{c}_{j t} / f_{j t} \text {. }
$$

It is reasonable to suppose that current consumption per equivalent capita is a distributed lag function of expenditures per equivalent capita. So ( 3.3 ) is modified as

(3.3') $\quad \bar{c}_{j t}=\sum_{k=0}^{M}\left(\rho_{j k} c_{j, t-k}\right) \quad(j=1,2, \ldots, n)$. 
I incorporate the family size and seasonality effects into the first specification of the utility function (3.6) as

$$
u=-g_{1 t} \exp \left(-\mu_{1} \bar{c}_{1 t}\right)-\ldots-g_{n t} \exp \left(-\mu_{n} \bar{c}_{n t}\right)
$$

where $g_{j t}(j=1,2, \ldots, n)$ serves to represent both seasonal variations in the instantaneous utility function and the family size effects. The resulting equation that corresponds to $(3.9)$ is

(3.9') $\quad \bar{c}_{j, t+1}-\bar{c}_{j t}=d_{j t}+e_{j, t+1} \quad(j=1,2, \ldots, n)$,

with

$\left(3.10^{\prime}\right) \quad d_{j t}=\mu_{j}^{-1}\left[\ln \left(1+r_{j, t+1}\right)+\ln (\delta)+\ln \left(g_{j, t+1} / g_{j t}\right)\right]$.

The family size and seasonality effects are incorporated into the second specification of the quadratic utility function as

$$
\left(3.11^{\prime}\right) \quad u=\left[a_{t}^{\prime} \bar{c}_{t}-(1 / 2) \bar{c}_{t}^{\prime} B \bar{c}_{t}\right] F_{t} \text {, }
$$

where $F_{t}$ is an overall index of family size and $a_{t}$ is an $n$-dimensional vector of seasonality factors. The resulting equation is again $\left(3.9^{\prime}\right)$ where $\bar{c}_{j t}$ is redefined as $\bar{c}_{j t}$ times $F_{t} / f_{j t}$ and $d_{j t}$ is a function of the change in the commodity-specific number of equivalent adults and of the seasonality factors in periods $t$ and $t+1$. In short, the family size effect is incorporated in (3.9') in the family size-adjusted consumption $\bar{c}$ and in the intercept term $d_{j t}$ and seasonality is incorporated in the intercept term. 
Substituting $\left(3.3^{\prime}\right)$ into $\left(3.9^{\prime}\right)$ one obtains the equation stated in terms of expenditures:

$(3.14)$

$$
\begin{gathered}
c_{j, t+1}-c_{j t}= \\
d_{j t}-\rho_{j 1}\left(c_{j t}-c_{j, t-1}\right)-\ldots-\rho_{j M}\left(c_{j, t-M+1}-c_{j, t-M}\right)+e_{j, t+1} \\
\quad(j=1,2, \ldots, n)
\end{gathered}
$$

where $\rho_{j 0}$ is normalized to be unity and it is understood that $d_{j t}$ varies from season to season and depends on changes in family size. Appendix B shows that approximately the same equation can be derived from a continuous-time model where c's are unit averages over periods of an arbitrarily given length. If the household's expectation as of $t$ of $c_{j, t+1}$ is denoted by $c_{j, t+1}^{e}$, equation (3.14) can be written as

(3.14') $c_{j, t+1}^{e}-c_{j t}=d_{j t}-p_{j 1}\left(c_{j t}-c_{j, t-1}\right)-\ldots-\rho_{j M}\left(c_{j, t-M+1}-c_{j, t-M}\right)$.

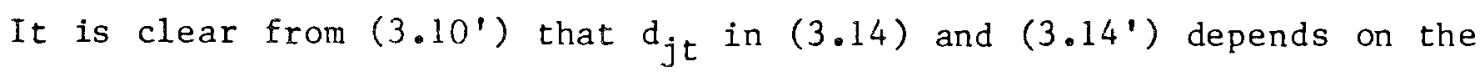
subjective rate of time preference $\delta$ and the (absolute) degree of risk aversion $\mu_{j}$ Equation (3.14) has a strong implication that nothing should Granger cause $c_{j t+1}-c_{j t}$ if expectations are rational [so that $E_{t}\left(e_{j, t+1}\right)=$ 0). So, for example, a fully anticipated tax cut should have no effect whatsoever when it is enacted; only unexpected policies can influence the behavior of expenditures. This can be easily tested on time-series data (provided that the real rate is constant), but to do the same thing on short panel data is difficult for two reasons. 
First, at any given point in time the forecast error $e_{j, t+1}$ can be correlated with any variable dated $t$ if the correlation is taken with respect to the distribution across households. ${ }^{15}$ Since the present panel has a small time dimension and a large cross-section dimension, estimation of equations like (3.14) will have to exploit the cross-section dimension. But the rational expectations hypothesis does not necessarily preclude correlation in cross-section between the right hand side variables and the forecast error term $e_{j, t+1}$. It is precisely for this reason that equation (3.14') rather than equation ( 3.14 ) forms a basis for the equation to be estimated in section 5. The second difficulty is that the length of the panel data is too short to allow for a realistic lag length in (3.14). But this can be overcome by the use of instrumental variables, as we will see in the next section.

My prior expectation is that the theory just presented will fail empirically. Probably the most likely source of fallure is liquidity constraints or borrowing constraints. Casual observations and my own experience show that expenditures by economics graduate students (in the U.S.) are largely determined by their current income and their ability to borrow. A most natural way to incorporate borrowing constraints is to let the interest rate be endogenous and depend on the household's income and asset position. But then the Euler equation ( 3.4 ) will become much more complicated, because the marginal benefit of foregoing one unit of expenditures consists not only of increased expenditures in the next period but also of improved credit conditions. Furthermore, the present data set has no information on assets and liabilities, so it is impossible to implement the idea of endogenous interest rates in a satisfactory fashion.

The view about borrowing constraints taken in this study is that part of the households in the population behaves according to the permanent income 
hypothesis described above while the remaining part does not. Households which do not follow the permanent income hypothesis are subject to borrowing constraints, in the sense that the marginal propensity to spend out of current disposable income is unity. If a constant fraction $\alpha_{j}$ of additional disposable income of constrained households goes to expenditures on cominodity $j$, the behavior of expenditures by constrained households is described by

$$
\begin{aligned}
& c_{j, t+1}-c_{j t}=\alpha_{j}\left(\frac{P Y D_{t+1}}{p_{j, t+1} f_{j, t+1}}-\frac{P Y D_{t}}{p_{j t} f_{j t}}\right) \quad(j=1,2, \ldots, n) \\
& \text { with } \sum_{j=1}^{n} \alpha_{j}=1,
\end{aligned}
$$

where PYD is nominal disposable income and $f_{j t}$ is the number of equivalent adults specific to commodity group $j$. If the household's expectation as of $t$ of $c_{j, t+1}$ and $P Y D_{t+1}$ are denoted by $c_{j, t+1}^{e}$ and $P Y D_{t+1}^{e}$, respectively, and if $p_{j, t+1}$ and $E_{j, t+1}$ are perfectly foreseen in period $t$, then this equation can be rewritten as

$$
\text { (3.15') } \quad c_{j, t+1}^{e}-c_{j t}=\alpha_{j} \operatorname{EDY}_{j t} \quad(j=1,2, \ldots, n) \quad \text { with } \quad \sum_{j=0}^{n} \alpha_{j}=1 \text {, }
$$

where

$$
\operatorname{EDY}_{j t}=\frac{\operatorname{PYD}_{t+1}^{e}}{P_{j, t+1}^{f}{ }_{j, t+1}}-\frac{P D_{t}}{P_{j t} F_{j t}}
$$

is family size-adjusted expected disposable income change. In section 5, a mixture of $\left(3.14^{\prime}\right)$ - the equation for the households which follow the permanent income hypothesis - and (3.15') -- the equation for constrained households - will be estimated. The next section discusses econometric 
issues concerning the estimation of (3.14') and (3.15').

\section{ECONOMETRIC ISSUES}

The main objective in the remaining part of this paper is to estimate the parameters of the two equations (3.14') and (3.15') that describe the behavior of unconstrained and constrained households. This section discusses three issues that should be taken into account when one deals with cross-section or panel data. They are: (i) individual (or household-specific) effects, (ii) measurement error, and (iii) heteroskedasticity. Most of the discussion in this section will be technical and rather lengthy. Nontechnical readers can skip to the last paragraph of this section without losing continuity.

I think it is reasonable to assume that the lag coefficients $\rho_{j k}$ in (3.14') are the same across households. Those are just a description of the mechanical relationship between expenditures and consumption; the shape of the lag distribution will be largely determined by the nature of the comnodity, not by (observable and unobservable) characteristics of the household. It is, however, probably unrealistic to assume that the rate of time preference $\delta$ and the degree of risk aversion $\mu_{j}(j=1,2, \ldots, n)$ are constant across households. They will most likely depend on the age of the household head and some other unobservable household characteristics. This means that the intercept term $d_{j t}$ in (3.14') depends not only on observable household characteristics such as age and change in family size but also on unobservable characteristics (individual effects). 16 One can always write $d_{j t}$ as:

(4.1) $\quad d_{j t}=$ linear function of $A G E$ and $A_{G E}^{2}+\varepsilon_{j t} \quad(j=1,2, \ldots, n)$ 
where AGE is the age of the household head and where the linear function of $A G E$ and $A G E^{2}$ is the least squares projection of $d_{j t}$ on $A G E, A G E^{2}$. So $\varepsilon_{j t}$ represents unobservable household characteristics that are uncorrelated with $A G E$ and $\mathrm{AGE}^{2}$. The theoretical discussion in section 3 implies that $d_{j t}$ also depends on change in family size and seasonality. Since estimation will be performed in the cross-section dimension for a fixed $t(t=4)$, there is no need to explicitly incorporate seasonality in (4.1). Family size in period 5 is not in the data set; I assume there is no change in family size from period 4 to period 5. This is why change in family size does not appear in (4.1). The unobservable individual effect (i.e., unobservable household characteristics) $\varepsilon_{j t}$ will be a part of the error term in the estimation equation. Another source of the error term is the truncation remainder. As the panel is only four quarters long, only three lags, namely $-p_{j 1}\left(c_{j 4}-c_{j 3}\right)-p_{j 2}\left(c_{j 3}-c_{j 2}\right)-p_{j 3}\left(c_{j 2}-c_{j 1}\right)$, can be included in the equation, and a part of the remaining lags, $\sum_{k=4}^{y} \rho_{j k}\left(c_{j, 5-k}-c_{j, 4-k}\right)$, has to be included in the error term. It is easy to see from (3.14) and (4.1) that the remaining lags can be written as the sum of three parts: ( $i$ ) the part that can be linearly predicted by $A G E$ and $\mathrm{AGE}^{2}$; (ii) the individual effect that are uncorrelated with $\mathrm{AGE}$ and $\mathrm{AGE}^{2}$; and (iii) a weighted sum of past forecast errors $e_{j, 5-k}(k \geq 4)$. The deviation of the sum of (ii) and (iii) from its population mean will be called the truncation remainder and denoted by $T_{\mathrm{j}}$. It is reasonable to assume that $A G E$ and $A G E^{2}$ are uncorrelated with (iii) above because the household can predict its future AGE perfectly. Thus the truncation remainder $\operatorname{TR}_{j}$ for commodity $j$ is the part of the remaining lags that are uncorrelated with $\mathrm{AGE}$ and $\mathrm{AGE}^{2}$. This is the second component of the error term.

If, in addition, there is measurement error in expenditures, the error 
term will have measurement error as the third component. ${ }^{17}$ Thus the estimation equation becomes

$$
\begin{aligned}
& c_{j 5}^{e}-c_{j 4}=1 \text { inear function of } A G E \text { and } A_{G E} \\
& -\rho_{j 1}\left(c_{j 4}-c_{j 3}\right)-\rho_{j 2}\left(c_{j 3}-c_{j 2}\right)-\rho_{j 3}\left(c_{j 2}-c_{j 1}\right)+v_{j},
\end{aligned}
$$

where

(4.3) $\quad v_{j}=\varepsilon_{j 4}-T R_{j}+$ measurement error in $c_{j 1}, c_{j 2}, c_{j 3}, c_{j 4}$ and $c_{j 5}^{e}$.

The equation ( $\left.3.15^{\prime}\right)$ that describes the behavior of constrained households becomes, in the presence of measurement error,

$$
c_{j 5}^{e}-c_{j 4}=\alpha_{j} E Y D_{j 4}+w_{j} \quad(j=1,2, \ldots, n)
$$

where $w_{j}$ is measurement error in $c_{j 5}^{e}-c_{j 4}$ and in EYD ${ }_{j 4}$.

There is no shortage of reasons why the error terms $v_{j}$ and $w_{j}$ in two equations (4.2) and (4.4) are correlated with the right hand side variables. Since the error term contains measurement error, there is the classical errors-in-variables problem. The truncation remainder, $\mathrm{TR}_{j}$, is obviously correlated with the first three lags, $c_{j 4}-c_{j 3}, c_{j 3}-c_{j 2}$, and $c_{j 2}-c_{j 1}$. since individual differences in the rate of time preference and in the degree of risk aversion affects the behavior of expenditures, the individual effect $\varepsilon_{j 4}$ is also correlated with the first three lags. But suppose there are available a set of instruments, $x_{j}$, for which

$$
E\left(v_{j} x_{j}\right)=0 \text { and } E\left(w_{j} x_{j}\right)=0 \quad(j=1,2, \ldots, n) .
$$


This assumption means that neither the individual effect, nor the truncation remainder, nor measurement error is correlated with $x_{j}$. The two variables AGE and $\mathrm{AGE}^{2}$ are valid instruments as it can be reasonably assumed that they are uncorrelated with measurement errors.

Let $\lambda$ be the fraction of constrained households in the population (from which the sample was drawn). Then (4.2) holds with probability $1-\lambda$ and (4.4) holds with probability $\lambda$. The following equation can be derived (see Appendix C):

$$
\text { (4.6) } \begin{aligned}
& c_{j 5}^{e}-c_{j 4}=\text { linear function of } A G E \text { and } A G E^{2} \\
& -(1-\lambda) \rho_{j 1}\left(c_{j 4}-c_{j 3}\right)-(1-\lambda) \rho_{j 2}\left(c_{j 3}-c_{j 2}\right)-(1-\lambda) \rho_{j 3}\left(c_{j 2}-c_{j 1}\right) \\
& +\lambda a_{j} E D Y_{j 4}+\eta_{j}, \quad \text { with } E\left(n_{j} x_{j}\right)=0 \quad(j=1,2, \ldots, n),
\end{aligned}
$$

where $E \mathrm{jY}_{\mathbf{j}}$, family size-adjusted expected change in disposable income, is defined in (3.16), and the error term $\eta_{j}$ is composed of the three components, namely the individual effect, the truncation remainder, and measurement errors. To derive $(4.6)$ it is necessary to assume that the fraction $\lambda$ is constant, independent of the right hand side variables and instruments. If this assumption sounds too strong, one can think of (4.6) as a device to test the permanent incoe hypothesis; testing for $\lambda=0$ amounts to a test of the hypothesis. Equation (4.6) can be estimated by two- or three-stage least squares with $x_{j}$ as instruments. This is the equation to be estimated in the next section.

The final econometric issue is heteroskedasticity. Since the present data set is a random sample, the variables in (4.6) are i.i.d. (independently 
and identically distributed) across households. So the unconditional variance of $\eta_{j}$ is constant. However, the conditional variance of $\eta_{j}$ conditional on $x_{j}$ is a function of $x_{j}$, in general. In order to carry out valid statistical inference the standard theory of two- and three-stage least squares is inadequate. Fortunately, however, the theory has recently been generalized to encompass heteroskedasticity (see, e.g. Chamberlain [1982]). I now briefly summarize it.

There are $\mathrm{n}$ equations to be estimated:

$(4.7)$

$$
y_{i j}=\delta_{j}^{\prime} z_{i j}+n_{i j} \quad(j=1,2, \ldots, n ; \quad i=1,2, \ldots, N)
$$

where $\delta_{j}$ is a vector of coefficients, $n$ is the number of commodity groups, $i$ is the household index, and $\mathrm{N}$ is the sample size (the number of households). The dependent variable $y_{i j}$ corresponds to $c_{j 5}^{e}-c_{j 4}$ of household $i$ and the vector of right hand side variables $z_{i j}$ corresponds to $\left(1, \operatorname{AGE}, \operatorname{AGE}^{2}, c_{j 4}-\right.$ $\left.c_{j 3}, c_{j 3}-c_{j 2}, c_{j 2}-c_{j 1}, E_{j 4}\right)$ pertaining to household $i$. The column vector of instruments $x_{i j}$ are orthogonal to $\eta_{i j}: \quad E\left(n_{i j} x_{i j}\right)=0$. The generalized two-stage least squares estimator of $\delta_{j}$ is given by

$$
\hat{\delta}_{j}=\left(z_{j}^{\prime} x_{j} \hat{\Psi}_{j j}^{-1} x_{j}^{\prime} z_{j}\right)^{-1}\left(z_{j}^{\prime} x_{j} \hat{\Psi}_{j j}^{-1} x_{j}^{\prime} y_{j}\right) \quad(j=1,2, \ldots, n),
$$

where $z_{j}$ and $x_{j}$ are matrices whose rows are $z_{i j}^{\prime}$ and $x_{i j}^{\prime}$, respectively, and $y_{j}$ is the $\mathbb{N}$-dimensional vector whose elements are $y_{i j}$ 's. The matrix $\hat{H}_{j j}$ in this experession is given by

$$
\hat{\Psi}_{j j}=\frac{1}{N} \sum_{i=1}^{N}\left[\left(y_{i j}-\tilde{\delta}_{j} z_{i j}\right)^{2} x_{i j} x_{i j}^{\prime}\right\} \quad(j=1,2, \ldots, n),
$$


where $\widetilde{\delta}_{j}$ is a consistent estimator of $\delta_{j}$. It can be shown (under a set of appropriate regularity conditions) that $\left(\hat{\delta}_{1}, \hat{\delta}_{2}, \ldots, \hat{\delta}_{n}\right)$ is asymptotically normal in the presence of conditional heteroskedasticity. The theory of three-stage least squares can be generalized to incorporate conditional heteroskedasticity in a similr fashion.

If the number of instruments $x_{i j}$ is equal to the number of the right hand side variables $z_{i j}$, then the above generalized two-stage least squares estimator reduces to the usual instrumental variables estimator

$(4.10)$

$$
\hat{\delta}_{j}=\left(X_{j}^{\prime} z_{j}\right)^{-1} x_{j}^{\prime} y_{j} \quad(j=1,2, \ldots, n),
$$

and the generalized three-stage least squares estimator also reduces to this estimator. It can be shown that the asymptotic variance-covariance matrix of $\hat{\delta}_{j}$ is consistently estimated by

(4.11) $\quad S_{z_{j} x_{j}}^{-1} \hat{\Psi}_{j j} S_{z_{j} x_{j}}^{-1} \quad(j=1,2, \ldots, n)$,

where $S_{z} x_{j}=\frac{I}{N} \sum_{i=1}^{N} z_{i j} x_{i j}^{\prime}$ and $\hat{\delta}_{j}$ is used in place of $\widetilde{\delta}_{j}$ in calculating $\hat{\Psi}_{j j}$, and that the asymptotic covariance matrix between $\hat{\delta}_{j}$ and $\hat{\delta}_{\ell}$ is consistently estimated by

$$
S_{z_{j} x_{j}}^{x_{j \ell}} \hat{\psi}_{z_{\ell} x_{\ell}} S^{-1} \quad(j, \ell=1,2, \ldots, n)
$$

where

$$
\left.\hat{\Psi}_{j \ell}=\frac{1}{N} \sum_{i=1}^{N}\left\{\left(y_{i j}-\hat{\delta}_{j} z_{i j}\right)\left(y_{i \ell}-\hat{\delta}_{i \ell}\right) x_{i j} x_{i \ell}^{\prime}\right)\right\} \text {. }
$$


If $z_{i j}=x_{i j}$, the estimator $(4.10)$ is the usual oLs estimator. Its heteroskedasticity-robust asymptotic variance is given by (4.11) with $z_{i j}=$ $x_{i j}$. This is the formula $I$ used in calculating the standard errors in Table 5 for the VAR mode1. Formulas $(4.10)-(4.13)$ are the ones I will use in calculating the point estimates and their associated standard errors for equation (4.6) in the next section.

To summarize: The equation to be estimated is (4.6) which explicitly recognizes that a certain fraction $\lambda$ of the population is liquidity constrained. This equation will be estimated in the cross-section dimension. Since the panel is only four quarters long, only three lagged expenditure changes can be included on the right hand side, and the remaining lags (the truncation remainder) are relegated to the error term. Also included in the error term are the individual effect (i.e., individual differences in the rate of time preference and the degree of risk aversion) and measurement error. This provides a reason for correlation between the error term and the right hand side variables. The equation will be estimated by instrumental variables in a way that is robust to heteroskedasticity.

\section{RESULTS}

To anticipate the results, identification of $\lambda$ (the fraction of liquidity constrained households in the population) turned out to be rather tenuous. So I first present the parameter estimates of the pure permanent income hypothesis represented by equation (4.6) with $\lambda=0$, and then turn to the estimation of $\lambda$.

The critical issue in estimating equation (4.6) with $\lambda=0$ by the generalized two-stage least squares is the choice of instruments. Valid 
instruments must be uncorrelated with the three components of the error term $\eta_{j}$, namely the individual effect, the truncation remainder, and measurement error. I include $\mathrm{AGE}$ and $\mathrm{AGE}^{2}$ in the set of instruments. As for the instruments for lagged expenditure changes $c_{j t}-c_{j, t-1}(t=2,3,4)$, I use the associated unexpected changes $c_{j t}-c_{j t}^{e}(t=2,3,4)$. It is reasonable to assume that unexpected changes are uncorrelated with the individual effect which is known to the household. As is shown in Table 6, there is some evidence of statistically significant correlation between unexpected expenditure changes and lagged actual expenditure changes, implying that unexpected changes can be correlated with the truncation remainder. But what Table 6 also tells us is that the correlation is small in size -- much smaller than the correlation of actual change with its own lagged changes. So the bias due to correlation of instruments with the truncation remainder will be small, if any. There is no a priori reason to preclude correlation between unexpected change and measurement error. I use unexpected changes as instruments because I think there is no other valid choice of instruments. But at least there is one case in which measurement error causes no problem. It is the case where actual expenditures $c_{j t}$ and its expectation $c_{j t}^{e}$ are subject to the same measurement error. In this case measured unexpected change $c_{j t}-c_{j t}^{e}$ is free from measurement error. If unexpected change contained a large measurement error, it would be serially correlated. But Table 6 shows no particularly strong autocorrelation in unexpected changes. Thus, the set of instruments for estimating equation (4.6) with $\lambda=0$ for commodity group $j$ is: (1, AGE, AGE ${ }^{2}, c_{j 4}-c_{j 4}^{e}, c_{j 3}-c_{j 3}^{e}$, $\left.c_{j 2}-c_{j 2}^{e}\right)$. The number of instruments is equal to the number of the right hand side variables. 18

The results of the estimation of $(4.6)$ with $\lambda=0$ by the generalized twostage least squares [which uses formulas (4.10) and (4.11)] are given in Panel 
A of Table 7 for the ten commodity groups. The intercept, the AGE and $\mathrm{AGE}^{2}$ coefficients are not reported because none of them are significant at 5 percent. All but one lag coefficients are highly significant. The estimated first three lag coefficients $\rho_{j 1}, \rho_{j 2}, \rho_{j 3}$ are small (but significant) for food ( $\mathrm{Cl}$ ) and very close to unity for durables (C4) and clothes (C3). This is very reasonable. What is (probably not really surprising but) revealing is the large lag coefficients for commodity groups (C5-C9) that are usually labeled as "services." Even though services are physically perishable, their psychological effect on households' preference is long-lasting. The lag coefficents for C5 seems unduly large because, if taken seriously, they mean that people derive more utility from the memory of a trip than from the trip itself. This is probably due to sampling error, as the standard errors for C5 is very high.

For later reference I report the parameter estimates by the ordinary least squares in Panel $\mathrm{B}$ of Table 7. The estimated lag coefficients are smaller than the estimates by the two-stage least squares, because of measurement errors and because the first three lagged changes are negatively correlated with the truncation remainder (as is predicted by the permanent income hypothesis).

The estimated model allows for no feedback from lagged expenditure changes on other commodity groups. It might be that the surprisingly high durability of services is due to the influence of lagged expenditures on, say, consumer durables. To check this, I expanded equation (4.6) with $\lambda=0$ to include lagged expenditure changes on other commodity groups. So the equation now has $c_{j 5}^{e}-c_{j 4}$ as the dependent variable, and AGE, $A_{G E}^{2}, c_{j t}-c_{j, t-1}$ ( $t=$ $2,3,4)$ and $c_{\ell t}-c_{\ell, t-1}(\ell \neq j, t=2,3,4)$ on the right hand side. This equation was estimated by the generalized two-stage least squares for the ten 
commodity groups $(j=1,2, \ldots, 10)$ with $A G E, A G E^{2}$, and the associated unexpected changes $c_{\ell t}-c_{\ell t}^{e}(\ell=1,2, \ldots, 10)$ as instruments. Table 8 reports pertinent Wald-type statistics for the hypothesis that lagged expenditure changes on other commodity groups have all zero coefficients. Except for C4 (consumer durables) and possibly C2 (rent, fuel and utilities), lagged expenditure changes on other commodities are totally insignificant. One possible reason for the rejection of the hypothesis for durables is that the equation for durables is misspecified. The equation was derived from the Euier equation (3.4) under the assumption of interior solution. But in any given quarter over forty percent of the households in the sample reported no expenditures on consumer durables. Since those households are at the corner solution, the Euler equation does not hold for durables. Some other estimation technique such as Tobit and Probit would be required in order to correctly treat the durables equation. The possible misspecification of the durables equation was, in fact, the main reason for not using the generalized three-stage least squares; by sticking to the (generalized) two-stage least squares I can avoid biases due to the transmission of misspecification in one equation to another.

I now turn to the estimation of equation (4.6) without the $\lambda=0$ restriction. I tried two alternative instruments for instrumenting EDY ${ }_{j 4}$, family size-adjusted expected disposable income change. One is family sizeadjusted expected normal income change, which is obtained by substituting YN

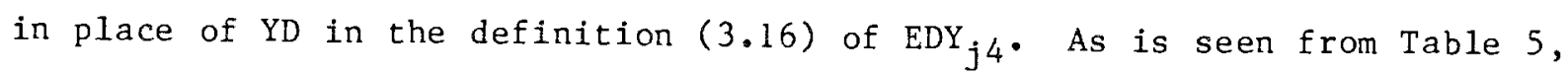
there is no significant feedback from lagged expenditures to normal income. So it is reasonable to assume that this instrument is uncorrelated with the truncation remainder. It is also plausible that the individual effect is uncorrelated with this instrument. If normal income is measured without 
error, there is no correlation between this instrument and measurement error in $E_{j^{4}}$. The generalized two-stage least squares estimate of $\lambda$ turned out to be .374 with a standard error of .131 . However, estimates of the lag coefficients $\rho_{j k}(k=1,2,3)$ became unduly high; for example, estimate of $\rho_{j l}$ for $j=5$ (recreatinal expenses) is 1.93 with a standard error of .69 . This is because the coefficients of lagged expenditures changes, which are $-(1-\lambda) \rho_{j k}$ 's, have changed very little compared with the case with $\lambda=0$. The second alternative instrument is (lagged) unexpected disposable income change, $\mathrm{YD}_{4}-\mathrm{YD}_{4}^{\mathrm{e}}$. This produced an estimate of -.12 !

The reason for such unreliable estimates is that expected disposable income change is hard to explain. A regression of $E_{j 4}$ on (family sizeadjusted) expected normal income change yields an $\mathrm{R}^{2}$ of only about .08. (The second instrument has even less explanatory power). Change in disposable income is dominated by temporary income.

After going through all this, I decided to treat $E_{j 4}$ as predetermined. That is, the instrument for $E{ }_{j 4}$ is $E{ } y_{4}$ itself. The parameter estimates for equation (4.6) with EDY $_{j 4}$ predetermined are given in Table 9. The estimates are rather implausible for a couple of reasons. For one thing, the estimate of $\alpha_{j}$ 's says that liquidity constrained households spends about fouty-four percent of their additional income on durables. This is a bit unrealistic. Probably this high estimate reflects the lumpiness of durables, an element that is not incorproated in the permanent income hypothesis. If durables are lumpy and if there are transaction costs in trading durables, it seems plausible that optimizing households try to synchronize the timing of durable purchases with income fluctuations. Another implausible fact about Table 9 is that the estimates of the lag coefficients are too high, particularly for durables (C4) and recreational expenses (C5). Again, estimates of 
- $(1-\lambda) \rho_{j k}(k=1,2,3)$ have changed very little; the estimates of the lag coefficients $\rho_{j k}$ in Table 9 are uniformly higher than those in Table $9 \mathrm{~A}$ by about fifteen percent. If reasonable estimates of the lag coefficients for durables are around unity, the estimate of $\lambda$ of .12 seems to be biased upwards.

To examine the source of the bias, I calculated the sample correlation between EDY $\mathrm{j}_{4}$ and lagged expenditure changes. This is reported in Table 10 . Although correlation is not very strong, there is a tendency that correlation becomes significantly negative as expenditure changes go back into the past. This suggests that $E_{j 4}$ is negatively correlated with the truncation remainder and hence is positively correlated with the error term $\eta_{j}$ which depends negatively on the truncation remainder. This provides an upward bias on the estimate of $\lambda$. On the other hand, measurement error in $E$ OY $_{j 4}$ implies a downward bias. Although the direction of the bias can go either way in general, an upward bias seems more likely because measurement error in disposable income is likely to be small for the present sample of workers' households.

On the whole, then, the empirical evidence has brought up quite clearly the surprisingly high durability of consumption expenditures while the evidence for liquidity constraints is weak. But is this consistent with timeseries data? This is an important question to ask because on the U.S. aggregate time-series data change in expenditures on nondurables and services as a whole is very much like white noise (Hall [1978]). The Japanese National Income Accounts have two different classifications of personal consumption expenditures. The first has four comodity groups by durability (nondurables, semidurables, durables, and services). Durable expenditures in this classificaiton seem to correspond to $\mathrm{C}_{4}$ (durables) in the present survey data. The 
second classification of expenditures is more in line with the one in the present survey data and has eight commodity groups: (i) food, beverages and tobacco, (ii) rents (including imputed rents), fuel, and utilities, (iii) clothes and footwears, (iv) furniture, household appliances, and housewares, (v) recreation and education, (vi) medical care, (vii) transportation and communication, and (viii) other. Roughly speaking, items (i), (ii) and (iii) correspond to $\mathrm{Cl}, \mathrm{C} 2$ and $\mathrm{C} 3$, respectively, and item (v) corresponds to the sum of $\mathrm{C} 5, \mathrm{C} 6$ and $\mathrm{C7}$ in the present survey data. For those commodity groups; third-order univariate autoregressions in changes are estimated by the ordinary least squares on the Japanese National Income Accounts data. The results are reported in Table 11. Except for durables, the estimated lag coefficients point to a substantial degree of durability. The time-series estimates in Table 11 are to be compared with the ordinary least squares estimates of equation (4.6) with $\lambda=0$ in Panel $B$ of Table 7 which also truncates the lag distribution at the third $\operatorname{lag}{ }^{19}$ The two sets of point estimates are fairly close to each other with the exception of the durable goods equation. The standard errors, however, are much larger for time-series estimates, reflecting a relatively small amount of information contained in aggregate time-series data. It thus seems fair to conclude that the panel evidence in this paper is consistent with the time-series evidence and that time-series data do not have enough power to detect consumption durability. The evidence presented so far is favorable to the permanent income hypothesis with consumption durability. However, the evidence is also consistent with the habit persistence hypothesis which posits that current expenditures are determined by lagged expenditures and current disposable income. 20 If this hypothesis is right, expenditure change on comnodity $j$ from period $3(1981: 04)$ to period $4(1982: Q 1)$ may be written as 21 
$(5.1)$

$$
\begin{gathered}
C_{j 4}-c_{j 3}=\text { Iinear function of } \mathrm{AGE}, \mathrm{AGE}^{2}, \mathrm{FSZ}_{4}-\mathrm{FSZ}_{3},\left(\mathrm{FSZ}_{4}-\mathrm{FSZ}_{3}\right)^{2} \\
+\beta_{j 1}\left(c_{j 3}-c_{j 2}\right)+\beta_{j 2}\left(c_{j 2}-c_{j 1}\right)+\gamma \mathrm{ADY}_{j 3}+\text { error, }
\end{gathered}
$$

where the error term includes the truncation remainder. In this equation $\mathrm{ADY}_{\mathrm{j} 3}$ represents family size-adjusted actual change in disposable income and is defined by

$$
A D Y_{j 3}=\frac{P_{4 D_{4}}}{P_{j 4} f_{j 4}}-\frac{P_{3} D_{3}}{P_{j 3} f_{j 3}}
$$

where, as before, PYD $_{t}$ is nominal disposable income, $P_{j t}$ is the price of commodity $j$, and $f_{j t}$ is the number of equivalent adults specific to commodity $j$ in period $t$. In contrast, the permanent income hypothesis that was developed in section 3 implies that actual expenditure change $c_{j 4}-c_{j 2}$ on commodity $j$ reacts to unexpected, not actual, disposable income change. To determine which hypothesis is more consistent with the data, I estimated the following equation which has both actual and unexpected disposable income changes:

$$
\begin{aligned}
& c_{j 4},-c_{j 3}=1 \text { linear function of } \mathrm{AGE}, \mathrm{AGE}^{2}, \mathrm{FSZ}_{4}-\mathrm{FSZ}_{3},\left(\mathrm{FSZ}_{4}-\mathrm{FSZ}_{3}\right)^{2} \\
&+\beta_{j 1}\left(c_{j 3}-c_{j 2}\right)+B_{j 2}\left(c_{j 2}-c_{j 1}\right)+\gamma_{j 1} \mathrm{ADY}_{j 3}+\gamma_{j 2} \text { UDY } \\
& j 3
\end{aligned}
$$

where family size-adjusted unexpected disposable income change $\mathrm{UDY}_{j 3}$ is defined by

(5.4) $\quad \operatorname{UDY}_{j 3}=\frac{\mathrm{PYD}_{4}}{\mathrm{P}_{j 4} \mathrm{f}_{j 4}}-\frac{\mathrm{PYD}_{4}^{\mathrm{e}}}{\mathrm{P}_{j 4} \mathrm{f} \mathrm{f}^{4}} \quad(j=1,2, \ldots, 10)$. 
The parameter estinates for equation (5.3), with unexpected expenditure change $c_{j 3}-c_{j 3}^{e}$ and $c_{j 2}-c_{j 2}^{e}$ as instruments for actual expenditure changes $c_{j 3}-$ $c_{j 2}$ and $c_{j 2}-c_{j 1}$, are given in Table 12. The results are again favorable to the permanent income hypothesis. First, the estimated coefficients of lagged expenditure changes are roughly in line with those in Table 7 and Table 9.22 The habit persistence hypothesis has no theory of why the lag coefficients take the kind of pattern in terms of signs and magnitudes reported in the Table. Second, the estimate of the coefficient of unexpected disposable income change of .29 is much higher than the estimate of actual disposable income change coefficient of .08 .23 Households respond to unexpected rather than actual income changes. This strongly suggests that households are forward-looking as is assumed in the permanent income hypothesis. The evidence in Table 12, however, does reject the permanent income hypothesis, because if the hypothesis is literally correct actual income change $\mathrm{ADY}_{j 3}$ should have no role in equation (5.3). One interpretation of the coefficient of actual income change of about eight percent is that it is the fraction of liquidity constrained households in the population. This number is fairly close to the estimate of $\lambda$ of about twelve percent.

Throughout this section I have ignored taste shocks which, if present, should form the fourth component of the error term. The instruments I have used for lagged expenditure changes - unexpected expenditure changes - are positively correlated with unforecastable taste shocks. If so, the lag coefficents $\rho_{j k}$ estimated in this section are biased upwards while the income coefficients remain unbiased. This may explain the significantly positive lag coefficients for food expenditures, if food is a priori believed to be perfectly perishable. However, as I argued toward the end of section 2, there seems to be no strong reason to believe that taste shocks are important 
in explaining the behavior of expenditure changes.

\section{CONCLUDING REMARKS}

The initial aim of the research reported here was to obtain a sharp estimate of the fraction of liquidity constrained households in the population by exploiting the large cross-section dimension of the data. This paper was not very successful on this account. The paper, however, was successful in highlighting the long-lasting effect of consumption expendtures for services and nondurables. Another useful by-product is the paper's demonstration of the strong response of expenditures to unexpected income changes without an explicit modelling of the income process, which leaves little doubt about the forward-looking nature of consumers.

The surprisingly high durablity of commodities has important implications for the econometrics of consumer demand and for macroeconomic stabilization policies. The usual specification in the econometrics of consumer demand is that the demand for nondurables and for services is a function of their current prices and total current expenditures. This is appropriate if the effect on preferences of nondurables and services is instantaneous. Otherwise the relevant variable is the user costs of capital, not current prices. 24 Expenditures and consumption should be treated like investment and capital, respectively.

Since the existing literature has ignored the durability of nondurables and services, its consensus estimate of the fraction of constrained households is likely to be biased upwards; what appears to be the excess sensitivity of expenditures to income may be merely due to the exclusion of lagged expenditures. Thus the effectiveness of countercyclical tax policy to control 
aggregate demand by changing disposable income may not be as great as is generally supposed. A potentially more important factor suggested by the durability of commodities is the real interest rate as a determinant of (the optimal stock of) consumption. If the real interest rate is controllable and if consumption is sensitive to the real rate, then policymakers can manipulate expenditures by the households that follow the permanent income hypothesis. The present paper was silent on the issue of the interest elasticity of consumption because of the small time-series dimension of the data.

Although the paper was able to reject the permanent income hypothesis, about a half of the excess sensitivity comes from durable purchases, as the results in Tables 9 and 12 show. It seems plausible that the apparent sensitivity of lumpy durable purchases can be generated by a model that allows for a small wedge between the borrowing and lending rates without significantly altering the behavior of nondurables and services expenditures. If so, the permanent income hypothesis with this minor modification applies to virtually all households. Furthermore, whether policymakers can exploit the short-run sensitivity of durables purchases in order to control aggregate consumer expenditures over a medium-run such as the length of a business cycle is another question.

More fundamentally, the empirical validity of the permanent income hypothesis casts serious doubts about the wisdom of countercyclical policies. The fact that expenditure changes follow univariate autoregressions with order higher than one implies that cyclical fluctuations in expenditures are a result of optimization on the part of forward-looking consumers. What, then, is the point in disturbing the optimally chosen time path of expenditures? 


\section{Appendix A: Proof of (3.5)}

This appendix proves (3.5) under two alternative assumptions.

Case 1: $M$ is small relative to $\mathrm{T}$.

Define

$$
t_{t+k}^{y_{t+k}}=E_{t}\left[\left(1+r_{j, t+1}\right) \delta \frac{\partial u\left(\bar{C}_{t+k+1}\right)}{\partial \bar{C}_{j, t+k+1}}-\frac{\partial u\left(\bar{C}_{t+k}\right)}{\partial \bar{C}_{j, t+k}}\right] .
$$

Then (3.4) becomes

$$
\sum_{k=0}^{M}\left(t_{t+k} \delta^{k} \rho_{j k}\right)=0
$$

This must be true at any future point in the remaining lifetime, so

$$
\sum_{k=0}^{L}\left(s_{s+k} \delta^{k} \rho_{j k}\right)=0, s=t, t+1, \ldots, t+T-1,
$$

where $L=\min (t+T-s, M)$ and $s_{t+T}=-E_{s}\left[\partial u\left(\bar{C}_{t+T}\right) / \partial \bar{C}_{j, t+T}\right]$. Apply the conditional expectations operator $E_{t}$ on both sides of this equation to obtain

$$
\sum_{k=0}^{L}\left(x_{s+k-t} \delta^{k} \rho_{j k}\right)=0, s=t, t+1, \ldots, t+T-1,
$$

where $x_{\tau}=t_{t}{ }_{t+\tau}$. This is an $m^{-t h}$ order difference equation in $x_{\tau^{*}}$ If the terminal value $x_{T}$ is given, (A.1) can determine the remaining value of $\mathrm{x}_{\mathrm{T}}$, namely $\mathrm{x}_{0}, \mathrm{x}_{1}, \ldots, \mathrm{x}_{\mathrm{T}-1}$. [The lifetime budget constraint (3.2) is necessary to determine the level of $\left.x_{T} \cdot\right]$ Since $\delta \rho_{j k}(k=1,2, \ldots M)$ is declining in $k$, the difference equation is unstable. Since the terminal value $x_{T}$ is finite, the initial value $x_{0}$ must be small. In fact, if $T$ is infinity, then $x_{0}=0$.

Case 2: $\rho_{j k}$ is declining geometrically in $k, p_{j, t+1}$ is known in $t$, and $r_{j, t+1}=r_{j, t+2}$. 


$$
\begin{aligned}
\text { Since } \rho_{j k}=\left(\rho_{j}\right)^{k},(3.3) \text { implies } \\
\qquad \bar{C}_{j t}=c_{j t}+\rho_{j} \bar{c}_{j, t-1} .
\end{aligned}
$$

Consider the following small deviation from the optimal decision rule: Reduce current expenditures on commodity $j$ by one unit and increase the next period's expenditure on commodity $j$ by $\rho_{j}$ units. Since this deviation means an additional saving of $\$ p_{j t}$ in period $t$, the additional income in period $t+1$ is $\left(1+R_{t}\right) p_{j t}-\rho_{j} p_{j, t+1}$ dollars. Note that this deviation leaves $\bar{c}_{j, t+1}$ unchanged from its level implied by the optimal decision rule. This small deviation should neither decrease nor increase the objective function, so that

$$
u_{j t}=\delta E_{t}\left[v_{t+1}\left(\left(1+R_{t}\right) p_{j t}-\rho_{j} p_{j, t+1}\right)\right]
$$

where $u_{j t}=\partial u\left(\bar{C}_{t}\right) / \partial \bar{C}_{j t}$ and $v_{t+1}$ is the marginal utility of income in period $t+1$. The marginal utility of income satisfies the equation

$$
e_{t}=\left(1+R_{t}\right) E_{t}\left(v_{t+1}\right)
$$

If $p_{j, t+1}$ is known at $t,(A .2)$ can be rewritten as

$$
u_{j t}=\left(1+r_{j, t+1}-\rho_{j}\right) p_{j, t+1} \delta E_{t}\left(v_{t+1}\right) .
$$

The right hand side of (A.4) has the interpretation of the "cost of capital" adjusted for the marginal utility of income. Now

$$
\begin{aligned}
& E_{t}\left[\left(1+r_{j, t+1}\right) \delta u_{j, t+1}\right] \\
= & E_{t}\left[\left(1+r_{j, t+1}\right) \delta\left(1+r_{j, t+2}-\rho_{j}\right) p_{j, t+2} \delta E_{t+1}\left(v_{t+2}\right)\right] \quad[\text { from (A.4)] } \\
= & E_{t}\left[\left(1+r_{j, t+1}\right)\left(1+r_{j, t+2}-\rho_{j}\right)\left(1+r_{j, t+2}\right)^{-1} p_{j, t+1} \delta v_{t+1}\right]
\end{aligned}
$$

[from (A.3)]

If $r_{j, t+1}=r_{j, t+2}$, this is equal to $u_{j t}$ by $(A .4)$. 


\section{Appendix B: Time Aggregation}

There is no reason that the length of a unit period for the household's optimization problem is exactly one quarter. The purpose of this appendix is to show that the quarterly model -- equation (3.14) in the text -- can be derived as an approximation to the continuous-time model.

The continuous-time versions of $(3.9)$ is

$$
\bar{C}\left(\tau^{\prime}\right)-\vec{C}(\tau)=e\left(\tau, \tau^{\prime}\right), \quad E_{\tau} e\left(\tau, \tau^{\prime}\right)=0 \text { for } \tau^{\prime}>\tau \text {, }
$$

where the subscript $j$ is dropped for notational simplicity and the intercept term $d_{j t}$ is ignored for simplicity. Let $t=0,1,2, \ldots$ be points in the continuous-time axis that mark the end of each quarter. Set $\tau=t$ and $\tau^{\prime}=t+1$ to obtain

$$
\bar{C}(t+1)-\bar{C}(t)=e(t, t+1), \quad E_{t} e(t, t+1)=0
$$

In the continuous-time model, $\overline{\mathrm{C}}$ is related to $\mathrm{C}$ by

$$
\bar{C}(\tau)=\int_{0}^{\infty} \rho(v) C(\tau-v) d v
$$

Combine (B.2) and (B.3) to get

$$
e(t, t+1)=\int_{0}^{\infty} \rho(v) C(t+1-v) d v-\int_{0}^{\infty} \rho(v) C(t-v) d v
$$

Now, consider the following step function as an approximation to $\rho(v)$ :

$$
\bar{\rho}(v)=\rho(0) \text { if } 0 \leqslant v<1, \bar{\rho}(v)=\rho(1) \text { if } 1 \leqslant v<2 \text {, etc. }
$$

Then one obtains

$$
\begin{aligned}
e(t, t+1) & =\int_{0}^{\infty} \vec{\rho}(v) c(t+1-v) d v-\int_{0}^{\infty} \bar{\rho}(v) c(t-v) d v \\
& =\rho(0)\left(C_{t+1}-C_{t}\right)+\rho(1)\left(C_{t}-C_{t-1}\right)+\ldots,
\end{aligned}
$$

where $C_{t}$ 's are unit-averages, namely 
(B.7) $\quad C_{t+1}=\int_{t}^{t+1} C(\tau) d \tau$.

Normalizing $\rho(0)$ to be unity, one obtains from (B.6) that

$(B .8)$

$$
\begin{aligned}
C_{t+1}-C_{t} & =-\rho(1)\left(C_{t}-C_{t-1}\right)-\rho(2)\left(C_{t-1}-C_{t-2}\right)-\ldots \\
& +e(t, t+1) .
\end{aligned}
$$

If period $t$ is the time interval between $t-1$ and $t$, the left hand side of (B.8) is the change in unit-averaged expenditures from period to period $t+1$. Note that $e(t, t+1)$ is orthogonal to information available at the end of period $t$, since $E_{t} e(t, t+1)=0$. 


\section{APPENDIX C: Derviation of (4.6)}

This appendix derives (4.6) under the assumption that $\lambda$, the fraction of constrained households in the sample, is an exogenously given constant. Write the two equations (4.2) and (4.4) compactly as

$$
y=\delta_{1} z_{1}+v \quad \text { for }(4 \cdot 2)
$$

$$
y=\delta_{2} z_{2}+w, \quad \text { for }(4.4)
$$

where the subscript $j$ is dropped for notational simplicity. Let a dummy variable $D$ take the value of unity if the household is constrained and zero if the household follows the permanent income hypothesis. The expected value of $D$ is $\lambda$. The two equations can be combined into one equation

$$
y=(1-D) \delta_{1} z_{1}+D \delta_{2} z_{2}+(1-D) v+D w
$$

If $\mathrm{D}$ is independent of $z_{1}, z_{2}, \mathrm{x}, \mathrm{v}, \mathrm{w}$, then the least squares projection of $\mathrm{y}$ on $\mathrm{x}, \mathrm{E}^{*}(\mathrm{y} \mid \mathrm{x})$, can be written from $(\mathrm{C.} .3)$ as

$$
E^{*}(y \mid x)=(1-\lambda) \delta_{1} E^{*}\left(z_{1} \mid x\right)+\lambda \delta_{2} E^{*}\left(z_{2} \mid x\right)
$$

Combining (C.3) and (C.4) one obtains

$$
y=(1-\lambda) \delta_{1} z_{1}+\lambda \delta_{2} z_{2}+\eta
$$

where

$$
\eta=y-E^{*}(y \mid x)-(1-\lambda) \delta_{1}\left[z_{1}-E^{*}\left(z_{1} \mid x\right)\right]-\lambda \delta_{2}\left[z_{2}-E^{*}\left(z_{2} \mid x\right)\right]
$$

By construction, $E^{*}(\eta \mid x)=0$, i.e., $E(n x)=0$ as required. Note that the conditional variance of $\eta$ conditional on $x$ is a function of $x$ by construction, even if the initial error terns $v$ and $w$ are conditionally homoskedastic. 


\section{FOOTNOTES}

1. In this paper the permanent income hypothesis is taken to mean that households optimize their intertemporal utility function subject to the lifetime budget constraint.

2. See King (1983) for a survey of recent contributions.

3. This example is due to Larry Summers,

4. The survey also has data on the amount of money that is given to members of the family other than the head. This is not considered in the analysis of this paper. The expenditure data refer to the full cost of purchases even though full payment may not have been made at the date of purchase.

5. No data on education are available. This is characteristic of most surveys in Japan.

6. The reason for doing this is to treat homeowners and nonhomeowners symmetrically。 This paper will work with changes in expenditures. Although the survey does not report imputed rents for homeowners, this will disappear when expenditure changes are taken.

7. One case reportad about 3.8 million yen for "other expenses" in period 1. This was a clear outlier. (The next highest value was about 1.2 million yen.) Four cases reported temporary income for period 1 in excess of 10 million yen. If these four cases are included, the sample standard deviation of temporary income in period 1 nearly quadruples, although the results to be reported in this paper are not changed in any important way (except for the results on temporary income). Another case reported temporary income in excess of $10 \mathrm{million}$ yen in period 2. The remaining seventh case reported expected normal incore for period 5 of 19,890 thousand yen. Since its actual normal income in periods $1,2,3$ and 4 is 1,980 thousand yen, I concluded that the number was wrong by one decimal point. 
8. For the commodity-specific number of equivalent adults, see Deaton and Muelbauer (1980).

9. The Annual Report on the Survey of Family Consumption (The Economic Planning Agency) reports quarterly time-series data from 1977:Q2 on average expenditures on the ten commodity groups. I estimated the multiplicative model of seasonality using this time-series data and then used the resulting seasonality factor to perform seasonal adjustment on the present data set.

10. If the real interest rate is equal to the subjective discount rate and if the instantaneous utility function is quadratic, then change in consumption is white noise, as Hall (1978) has shown. If, in addition, the first-order coefficients in the quadratic utility function is subject to taste shocks, then change in consumption is a white noise process plus a moving average of taste shocks. This was poinied out to me by Robert Flood.

11. The Family Income and Expenditure Survey, compiled by the Prime Minister's Office of Japan, is a diary survey on monthly expenditures on over several hundred commodity groups. Since one-sixth of the sample is replaced by new households every month, it is possible to create a sixmonth panel of monthly expenditures. A forthcoming study done at the Economic Planning Agency contains calculation of the autocorrelation coefficients for monthly expenditure changes. The first order autocorrelation coefficient for food is close to -0.4 on average.

12. This VAR model is estimated on family size-unadjusted data because I thought the interpretation of the VAR coefficients became more straightforward. The coefficients estimated on family size-adjusted data are virtually identical. The significance of the lag coefficients is determined by heteroskedasticity-robust standard errors. See section 4 for more details on how to calculate them. Four additional variables -$\mathrm{AGE}, \mathrm{AGE}^{2}, \mathrm{FSZ}_{4}-\mathrm{FSZ}_{3}$ and $\left(\mathrm{FSZ}_{4}-\mathrm{FSZ}_{3}\right)^{2} \ldots$ are also included on the right-hand side of the equations, but their estimated coefficients are not reported in Table 5. The lagged expenditure coefficients in the YT 
("temporary" income) equation are large in absolute value. This is due to seasonality in YT. If seasonally adjusted data on expenditures and income are used, the coefficients become must smaller in absolute value.

13. To economize notation, bequests are not considered, although it is straightforward to do so.

14. So the omission of leisure in our model does not seem to cause any serious problem. Anyway, there are rio data on labor supply in the present data set.

15. This is pointed out in Chamberlain (1982). Suppose, for example, there is a totally unexpected income tax reform in period that slashes the marginal tax rates for the rich. The forecast error $\mathrm{YD}_{t}-\mathrm{YD}_{t}^{\mathrm{e}}$ will be positive for the rich and negative for the poor. So the correlation between $\mathrm{YD}_{t}-\mathrm{YD}_{t}^{\mathrm{e}}$ and $\mathrm{YD}_{\mathrm{t}-1}$ across households, which equals

$$
\operatorname{plim}_{N \rightarrow \infty} N^{-1} \sum_{i=1}^{N}\left(Y_{i t}-Y D_{i t}^{e}\right) Y D_{i, t-1}
$$

(where $\mathrm{N}$ is the sample size and $\mathrm{i}$ indexes households), is positive. The mean of forecast errors can also differ from zero, because everyone can be wrong in the same direction at any given point in time. The household subscript $i$ has been dropped in the text.

16. The intercept term also depends on the after-tax real rate $r_{j, t+1}$. Since interest income is virtually tax-free in Japan, it is reasonable to assume that $\mathbf{r}_{j, t+1}$ is the same across households.

17. In what follows, I will ignore taste shocks. The implication of taste shocks for parameter estimtes will be discussed in the last paragraph of section 5 .

18. Unexpected expenditure changes in other commodities, $c_{\ell t}-c_{\ell t}^{e}(\ell \neq j)$, could also be used as instruments in estimating the equation for commodity $j$, but they are almost uncrorrelated with actual expenditure changes on commodity $j$ and so no significant efficiency gain will be accomplished. 
19. The time-series estimates in Table 11 assume that the real rates are constant over time.

20. Brown (1952)'s statement of the habit persistence hypothesis is as follows: "...the lag effect in consumer demand was produced by the consumption habits which people formed as a result of past consumption. The habits, customs, standards, and levels associated with real consumption previously enjoyed become 'impressed' on the human physcological and psychological systems and this produces an inertia or 'hysteresis' in consumer behavior." Brown summarizes his hypothesis in his equation 4: $C$ $=a_{0}+a_{1} Y+a_{2} C_{-1}+u$, where $Y$ is current income and $C_{-1}$ is lagged consumption.

21. Changes from period 3 to period 4 are considered because actual changes from period 4 to period 5 are unobservable.

22. The lag coefficients for food expenditures in Table 12 are considerably larger than those in Tables 7 and 9. This is probably due to multiplicative seasonality. The dependent variable in Table 12 is expenditure change from the fourth quarter to the first quarter of the following year. The first lag is expenditure change from the third to the fourth quarter, which is strongly negatively correlated with the dependent variable because of the high level of expenditures in the fourth quarter. The use of the data that are adjusted for multiplicative seasonality did produce smaller point estimates for the lag coefficients for food. There are, however, costs associated with the use of seasonally adjusted data. The formula (3.3) that links expenditures to cnsumpution should be in nonseasonally adjusted data. It does not seem sensible to suppose the equation (3.15) for liquidity constrained households holds on seasonally adjusted data. Anyway, since there is not much seasonality in expenditures in the first and second quarters of the year, the results in Tables 7-9 are robust to multiplicative seasonality.

23. If expected and unexpected income changes rather than actual and unexpected income changes are used, then the expected income change coefficient will be .08 and the unexpected income change coefficient will 
be .37 .

24. See (A.4) in Appendix A for a derivation.

\section{REFERENCES}

BROWN, T. M. "Habit Persistence and Lags in Consumer Behaviour." Econometrica 20 (July 1952): 355-371.

CHAMBERLAIN, GARY, "Panel Data." in: The Handbook of Econometrics, $M$. Intrilligator and Z. Grillichs ed.

DEATON, ANGUS, and MUELlBAUER, JOHN. Economics and Consumer Behavior, Cambridge University Press, 1980.

HALL, ROBERT E. "Stochastic Implications of the Life Cycle-Permanent Income Hypothesis: Theory and Evidence." Journal of Political Economy 86 (December 1978): 971-987.

HALL, ROBERT E., and MISHIKIN, FREDERIC S, "The Sensitivity of Consumption to Transitory Income: Estimates from Panel Data on Households." Econometrica 50 (March 1982): 461-481.

KING, MERVIN. "The Economics of Saving: A Survey of Recent Contributions." National Bureau of Economic Research Working Paper No. 1247, December 1983. 
TABLE 1

MEANS AND STANDARD DEVIATIONS OF LEVELS

A. Family Size-Unadjusted

\begin{tabular}{|c|c|c|c|c|}
\hline Variable & $1981: Q 2$ & $1981: Q 3$ & $1981: Q 4$ & $1982: Q 1$ \\
\hline $\mathrm{C} 1$ & $\begin{array}{l}212.6 \\
(83.7)\end{array}$ & $\begin{array}{l}217.5 \\
(84.2)\end{array}$ & $\begin{array}{l}240.7 \\
(96.6)\end{array}$ & $\begin{array}{l}215.7 \\
(86.6)\end{array}$ \\
\hline $\mathrm{C} 2$ & $\begin{array}{l}65.9 \\
(44.2)\end{array}$ & $\begin{array}{c}64.7 \\
(43.0)\end{array}$ & $\begin{array}{c}74.3 \\
(47.6)\end{array}$ & $\begin{array}{c}74.3 \\
(44.0)\end{array}$ \\
\hline C3 & $\begin{array}{l}52.1 \\
(73.5)\end{array}$ & $\begin{array}{l}50.7 \\
(78.5)\end{array}$ & $\begin{array}{c}70.8 \\
(73.5)\end{array}$ & $\begin{array}{c}53.0 \\
(61.1)\end{array}$ \\
\hline$C 4$ & $\begin{array}{c}58.9 \\
(165.9)\end{array}$ & $\begin{array}{c}59.6 \\
(179.1)\end{array}$ & $\begin{array}{c}64.1 \\
(139.8)\end{array}$ & $\begin{array}{c}41.5 \\
(119.4)\end{array}$ \\
\hline C5 & $\begin{array}{r}33.5 \\
(50.6)\end{array}$ & $\begin{array}{c}52.6 \\
(66.4)\end{array}$ & $\begin{array}{c}41.2 \\
(52.9)\end{array}$ & $\begin{array}{c}34.1 \\
(51.7)\end{array}$ \\
\hline C6 & $\begin{array}{c}26.6 \\
(31.3)\end{array}$ & $\begin{array}{c}26.8 \\
(38.4)\end{array}$ & $\begin{array}{c}28.3 \\
(33.1)\end{array}$ & $\begin{array}{c}25.6 \\
(24.4)\end{array}$ \\
\hline$C 7$ & $\begin{array}{c}60.8 \\
(110.0)\end{array}$ & $\begin{array}{c}48.4 \\
(77.2)\end{array}$ & $\begin{array}{c}51.8 \\
(83.0)\end{array}$ & $\begin{array}{c}64.9 \\
(132.1)\end{array}$ \\
\hline $\mathrm{C} 8$ & $\begin{array}{c}21.0 \\
(38.7)\end{array}$ & $\begin{array}{l}21.9 \\
(31.9)\end{array}$ & $\begin{array}{c}24.2 \\
(40.0)\end{array}$ & $\begin{array}{c}22.2 \\
(39.3)\end{array}$ \\
\hline $\mathrm{Cg}$ & $\begin{array}{c}52.8 \\
(114.5)\end{array}$ & $\begin{array}{l}55.9 \\
(80.3)\end{array}$ & $\begin{array}{c}74.6 \\
(98.5)\end{array}$ & $\begin{array}{c}57.2 \\
(72.2)\end{array}$ \\
\hline C10 & $\begin{array}{l}76.9 \\
(73.5)\end{array}$ & $\begin{array}{l}78.9 \\
(76.7)\end{array}$ & $\begin{array}{c}88.3 \\
(81.3)\end{array}$ & $\begin{array}{l}70.3 \\
(60.8)\end{array}$ \\
\hline$Y N$ & $\begin{array}{c}681.5 \\
(276.6)\end{array}$ & $\begin{array}{c}688.4 \\
(291.2)\end{array}$ & $\begin{array}{c}693.8 \\
(292.9)\end{array}$ & $\begin{array}{c}686.9 \\
(282.9)\end{array}$ \\
\hline$Y T$ & $\begin{array}{c}202.7 \\
(337.3)\end{array}$ & $\begin{array}{c}214.1 \\
(244.6)\end{array}$ & $\begin{array}{c}446.8 \\
(366.4)\end{array}$ & $\begin{array}{c}03.1 \\
(121.8)\end{array}$ \\
\hline
\end{tabular}

NOTE. - - Standard deviations are in parentheses. The numbers for expenditures and income are stated in thousands of 1980 yen. 
TABLE 1 (Continued)

B. FAMILY SIZE-ADJUSTED

\begin{tabular}{|c|c|c|c|c|}
\hline Variable & $1981: Q 2$ & $1981: Q 3$ & $1981:$ Q4 & $1982: Q 1$ \\
\hline$C_{1}$ & $\begin{array}{l}157.5 \\
(58.1)\end{array}$ & $\begin{array}{l}160.7 \\
(56.6)\end{array}$ & $\begin{array}{l}177.6 \\
(64.8)\end{array}$ & $\begin{array}{l}159.2 \\
(59.7)\end{array}$ \\
\hline $\mathrm{C} 2$ & $\begin{array}{c}56.1 \\
(37.6)\end{array}$ & $\begin{array}{c}55.1 \\
(36.2)\end{array}$ & $\begin{array}{c}63.2 \\
(39.9)\end{array}$ & $\begin{array}{c}63.3 \\
(37.2)\end{array}$ \\
\hline $\mathrm{C3}$ & $\begin{array}{c}42.6 \\
(60.2)\end{array}$ & $\begin{array}{c}41.3 \\
(63.8)\end{array}$ & $\begin{array}{c}57.8 \\
(60.9)\end{array}$ & $\begin{array}{l}43.0 \\
(49.5)\end{array}$ \\
\hline C4 & $\begin{array}{c}51.5 \\
(142.1)\end{array}$ & $\begin{array}{c}51.8 \\
(151.0)\end{array}$ & $\begin{array}{c}56.4 \\
(123.4)\end{array}$ & $\begin{array}{c}36.3 \\
(102.2)\end{array}$ \\
\hline C5 & $\begin{array}{c}30.0 \\
(46.2)\end{array}$ & $\begin{array}{c}47.0 \\
(59.7)\end{array}$ & $\begin{array}{c}36.8 \\
(47.7)\end{array}$ & $\begin{array}{c}30.5 \\
(47.2)\end{array}$ \\
\hline C6 & $\begin{array}{c}21.1 \\
(23.9)\end{array}$ & $\begin{array}{c}21.3 \\
(31.3)\end{array}$ & $\begin{array}{c}22.4 \\
(26.4)\end{array}$ & $\begin{array}{c}20.3 \\
(19.0)\end{array}$ \\
\hline$C 7$ & $\begin{array}{c}41.6 \\
(78.0)\end{array}$ & $\begin{array}{c}33.0 \\
(57.2)\end{array}$ & $\begin{array}{c}35.0 \\
(58.5)\end{array}$ & $\begin{array}{c}43.6 \\
(88.4)\end{array}$ \\
\hline c8 & $\begin{array}{c}19.7 \\
(37.1)\end{array}$ & $\begin{array}{c}20.5 \\
(30.3)\end{array}$ & $\begin{array}{c}22.7 \\
(38.6)\end{array}$ & $\begin{array}{c}20.6 \\
(36.1)\end{array}$ \\
\hline $\mathrm{Cg}$ & $\begin{array}{c}52.9 \\
(104.1)\end{array}$ & $\begin{array}{c}56.0 \\
(80.6)\end{array}$ & $\begin{array}{c}74.8 \\
(98.3)\end{array}$ & $\begin{array}{l}57.3 \\
(72.5)\end{array}$ \\
\hline C10 & $\begin{array}{c}69.7 \\
(65.9)\end{array}$ & $\begin{array}{c}71.7 \\
(70.5)\end{array}$ & $\begin{array}{c}80.0 \\
(72.7)\end{array}$ & $\begin{array}{c}63.8 \\
(55.1)\end{array}$ \\
\hline
\end{tabular}

NOTE. - - Standard deviations are in parentheses. The numbers for expenditures are stated in thousands of 1980 yen and are per two
equivalent adults. 


\section{TABLE 2}

ESTIMATES OF THE MULTIPLICATIVE MODEL OF FAMILY SIZE

\begin{tabular}{|c|c|c|c|c|c|c|c|c|}
\hline \multirow{2}{*}{$\begin{array}{l}\text { Independent } \\
\text { Variable, } \\
\text { Log of: }\end{array}$} & \multicolumn{6}{|c|}{ Family Size Dummies } & \multirow{2}{*}{$R^{2}$} & \multirow{2}{*}{$\begin{array}{l}\text { Sample } \\
\text { Size }\end{array}$} \\
\hline & F3 & $\mathrm{F} 4$ & F5 & F6 & FT & F8+ & & \\
\hline $\mathrm{C}_{1}$ & .232 & .326 & .423 & .530 & .644 & .659 & .146 & 8,040 \\
\hline$C 2$ & .112 & .221 & .169 & .225 & .264 & .454 & .018 & 8,027 \\
\hline C3 & .125 & .230 & .328 & .385 & .392 & .512 & .017 & 7,841 \\
\hline $\mathrm{CA}$ & .133 & .092 & .241 & .215 & .251 & .434 & .004 & 4,849 \\
\hline$C 5$ & .097 & .081 & .218 & .255 & .258 & .233 & .006 & 7.163 \\
\hline C6 & .150 & .286 & .326 & .392 & .315 & .189 & .024 & 7.993 \\
\hline$C 7$ & .190 & .443 & .533 & .553 & .481 & .245 & .021 & 5.830 \\
\hline C8 & -.001 & -.029 & .171 & .348 & .173 & .355 & .009 & 7,353 \\
\hline $\mathrm{CP}$ & -.009 & -.062 & .005 & .205 & .254 & .444 & .007 & 7,918 \\
\hline C10 & .109 & .069 & .175 & .168 & .224 & .418 & .005 & 8,019 \\
\hline
\end{tabular}

NOTE. -- Cases with the zero for the dependent variable are deleted in calculatirig regression coefficients. Intercept terms are not reported. F8t is the dummy variable for family of size 8 or more. 
TABLE 3

MEANS AND STANDARD DEVIATIONS OF CHANGES

\begin{tabular}{|c|c|c|c|}
\hline $\operatorname{Variable}(x)$ & $x_{2}-x_{1}$ & $x_{3}-x_{2}$ & $x_{4}-x_{3}$ \\
\hline $\mathrm{C}_{1}$ & $\begin{array}{r}3.20 \\
(35.3)\end{array}$ & $\begin{array}{l}16.91 \\
(35.5)\end{array}$ & $\begin{array}{l}-18.45 \\
(40.7)\end{array}$ \\
\hline $\mathrm{C} 2$ & $\begin{array}{l}-1.05 \\
(27.7)\end{array}$ & $\begin{array}{r}8.15 \\
(27.5)\end{array}$ & $\begin{array}{r}.06 \\
(27.1)\end{array}$ \\
\hline $\mathrm{C3}$ & $\begin{array}{c}-1.29 \\
(64.4)\end{array}$ & $\begin{array}{r}16.44 \\
(62.2)\end{array}$ & $\begin{array}{l}-14.81 \\
(57.8)\end{array}$ \\
\hline $\mathrm{C4}$ & $\begin{array}{r}.29 \\
(191.5)\end{array}$ & $\begin{array}{r}4.58 \\
(178.5)\end{array}$ & $\begin{array}{r}-20.01 \\
(152.7)\end{array}$ \\
\hline C5 & $\begin{array}{l}17.00 \\
(63.7)\end{array}$ & $\begin{array}{l}-10.24 \\
(58.7)\end{array}$ & $\begin{array}{r}-6.27 \\
(56.5)\end{array}$ \\
\hline C6 & $(32.6)$ & $\begin{array}{r}1.08 \\
(33.9)\end{array}$ & $\begin{array}{c}-2.10 \\
(23.4)\end{array}$ \\
\hline$C 7$ & $\begin{array}{r}-8.59 \\
(50.9)\end{array}$ & $\begin{array}{r}2.00 \\
(43.8)\end{array}$ & $\begin{array}{r}8.53 \\
(74.4)\end{array}$ \\
\hline C8 & $(40.77)$ & $\begin{array}{r}2.18 \\
(40.8)\end{array}$ & $\begin{array}{l}-2.04 \\
(46.5)\end{array}$ \\
\hline C9 & $\begin{array}{r}3.05 \\
(118.0)\end{array}$ & $\begin{array}{r}18.84 \\
(103.0)\end{array}$ & $\begin{array}{r}-17.47 \\
(101.2)\end{array}$ \\
\hline$C_{10}$ & $\begin{array}{r}2.04 \\
(65.9)\end{array}$ & $\begin{array}{r}8.27 \\
(70.6)\end{array}$ & $\begin{array}{l}-15.15 \\
(61.9)\end{array}$ \\
\hline$Y N$ & $\begin{array}{r}6.85 \\
(117.1)\end{array}$ & $\begin{array}{r}5.41 \\
(104.0)\end{array}$ & $\begin{array}{r}-6.82 \\
(102.6)\end{array}$ \\
\hline YT & $\begin{array}{r}11.35 \\
(421.0)\end{array}$ & $\begin{array}{r}232.69 \\
(362.5)\end{array}$ & $\begin{array}{r}-383.69 \\
(350.5)\end{array}$ \\
\hline
\end{tabular}

NOTE. -- Standard deviations are in parentheses. Expenditures are family size-adjusted. Income is not family size-adjusted. 
TABLE 4

SAMPLE AUTOCORRELATION OF CHANGES

\begin{tabular}{|c|c|c|c|c|}
\hline \multirow{3}{*}{ Variable } & \multirow{2}{*}{\multicolumn{2}{|c|}{$\frac{\text { Seasonally Unadjusted }}{\text { autocorrelation }}$}} & \multicolumn{2}{|c|}{ Seasonally Adjusted } \\
\hline & & & \multicolumn{2}{|c|}{ autocorrelation } \\
\hline & $\begin{array}{l}\text { first } \\
\text { order }\end{array}$ & $\begin{array}{l}\text { second } \\
\text { order }\end{array}$ & $\begin{array}{l}\text { first } \\
\text { order }\end{array}$ & $\begin{array}{l}\text { second } \\
\text { order }\end{array}$ \\
\hline $\mathrm{C1}$ & $\begin{array}{l}-.264^{\star \star \star} \\
-.472^{\star \star \star}\end{array}$ & $-.131^{\star \star \star}$ & $\begin{array}{l}-.291^{\star \star \star} \\
-.401^{\star \star \star}\end{array}$ & $-.122^{\star \star \star}$ \\
\hline $\mathrm{C} 2$ & $\begin{array}{l}-.289^{\star \star \star} \\
-.539^{\star \star \star}\end{array}$ & -.034 & $\begin{array}{l}-.326^{\star \star \star} \\
-.504^{\star \star \star}\end{array}$ & -.034 \\
\hline C3 & $\begin{array}{l}-.425^{\star \star \star} \\
-.435^{\star \star \star}\end{array}$ & $-.130^{\star \star \star}$ & $\begin{array}{l}-.515^{\star \star \star} \\
-.267^{\star \star \star}\end{array}$ & $-.104^{\star \star \star}$ \\
\hline $\mathrm{C4}$ & $\begin{array}{l}-.541^{\star \star \star} \\
-.484^{\star \star \star}\end{array}$ & .002 & $\begin{array}{l}-.576^{\star \star \star} \\
-.368^{\star \star \star}\end{array}$ & .021 \\
\hline C5 & $\begin{array}{l}-.593^{\star \star \star} \\
-.318^{\star \star}\end{array}$ & $-.187^{\star \star \star}$ & $\begin{array}{l}-.405^{\star \star \star} \\
-.381^{\star \star \star}\end{array}$ & $-.171^{\star \star \star}$ \\
\hline C6 & $\begin{array}{l}-.653^{\star \star \star} \\
-.493^{\star \star \star}\end{array}$ & .010 & $\begin{array}{l}-.675^{\star \star \star} \\
-.462^{\star \star \star}\end{array}$ & .010 \\
\hline$C 7$ & $\begin{array}{l}-.432^{\star \star \star} \\
-.297^{\star \star \star}\end{array}$ & $.085^{\star \star \star}$ & $\begin{array}{l}-.519^{\star \star \star} \\
-.335^{\star \star \star}\end{array}$ & $.130 * \star \star$ \\
\hline C8 & $\begin{array}{l}-.357^{\star \star \star} \\
-.524^{\star \star}\end{array}$ & -.010 & $\begin{array}{l}-.353^{\star \star \star} \\
-.474^{\star \star \star}\end{array}$ & -.005 \\
\hline $\mathrm{Cg}$ & $\begin{array}{l}-.345^{\star \star \star} \\
-.634^{\star \star \star}\end{array}$ & $-.038^{*}$ & $\begin{array}{l}-.400^{\star \star \star} \\
-.493^{\star \star \star}\end{array}$ & -.032 \\
\hline C10 & $\begin{array}{l}-.468^{\star \star \star} \\
-.534^{\star \star \star}\end{array}$ & .057 & $\begin{array}{l}-.501^{\star \star \star} \\
-.465^{\star \star \star}\end{array}$ & $-.050^{\star}$ \\
\hline$Y N$ & $\begin{array}{l}-.333^{\star \star \star} \\
-.333^{\star \star \star}\end{array}$ & $-.065^{\star \star}$ & $\begin{array}{l}-.335^{\star \star \star} \\
-.328^{\star \star \star}\end{array}$ & $-.060^{\star *}$ \\
\hline$Y T$ & $\begin{array}{l}-.580^{\star \star \star} \\
-.732^{\star \star \star}\end{array}$ & $.112^{\star \star \star}$ & $\begin{array}{l}-.736^{\star \star \star} \\
-.087^{\star \star \star}\end{array}$ & $-.073^{\star \star}$ \\
\hline
\end{tabular}


NOTE TO TABLE 4. -- Two first-order autocorrelation coefficients are calculated. The numbers that first appear in the column for first-order autocorrelation are the correlation coefficient beteen $X_{3}-x_{2}$ and $X_{2}-X_{1}$, and the numbers that appear below them are the correlation coefficient of $X_{4}-X_{3}$ and $X_{3}-X_{2}(X=C 1, C 2, \ldots, Y N, Y T)$. Expenditures are family size-adjusted.

* Significant at the 5 percent level. ** Significant at the 1 percent level. *** Significant at the .1 percent level. 


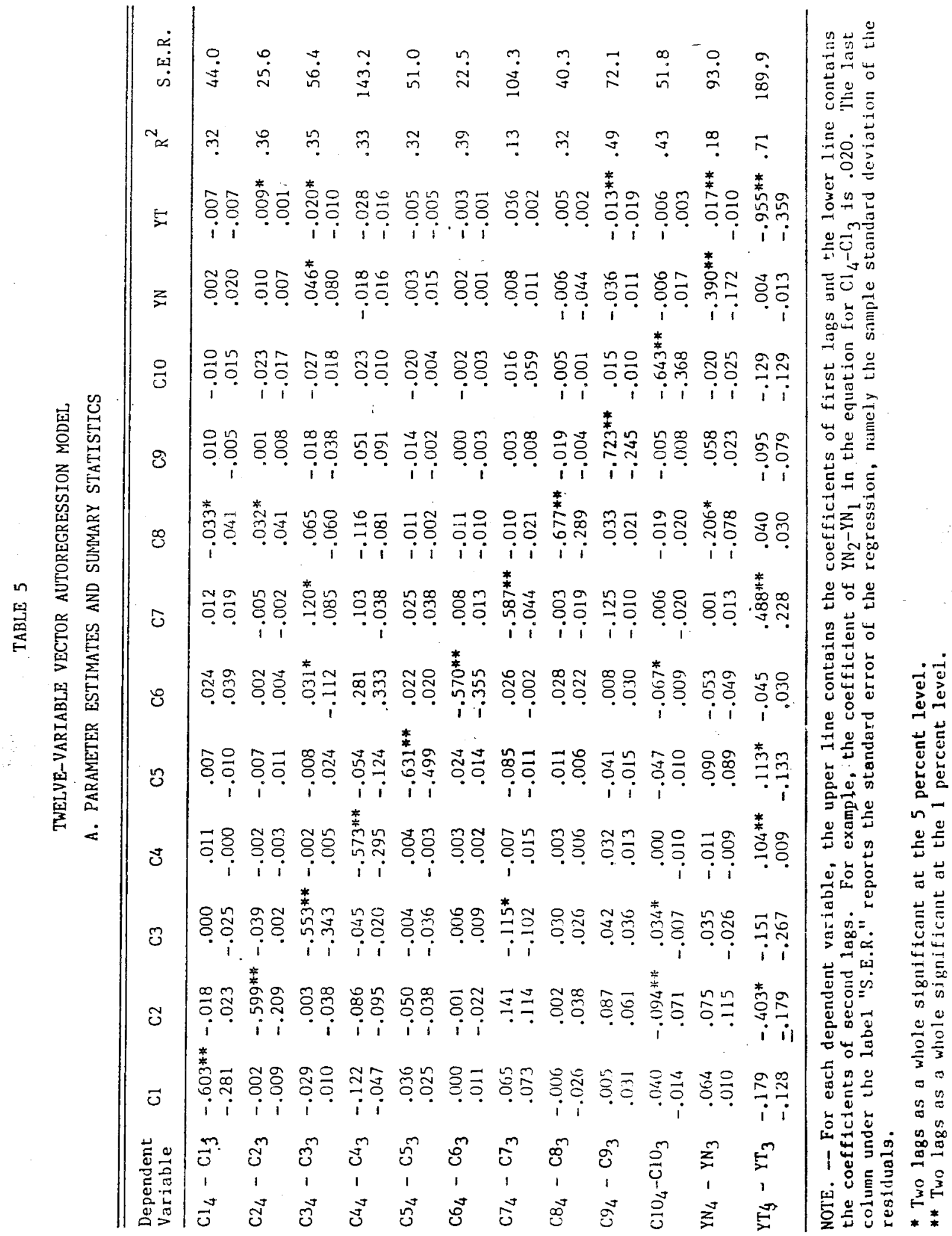




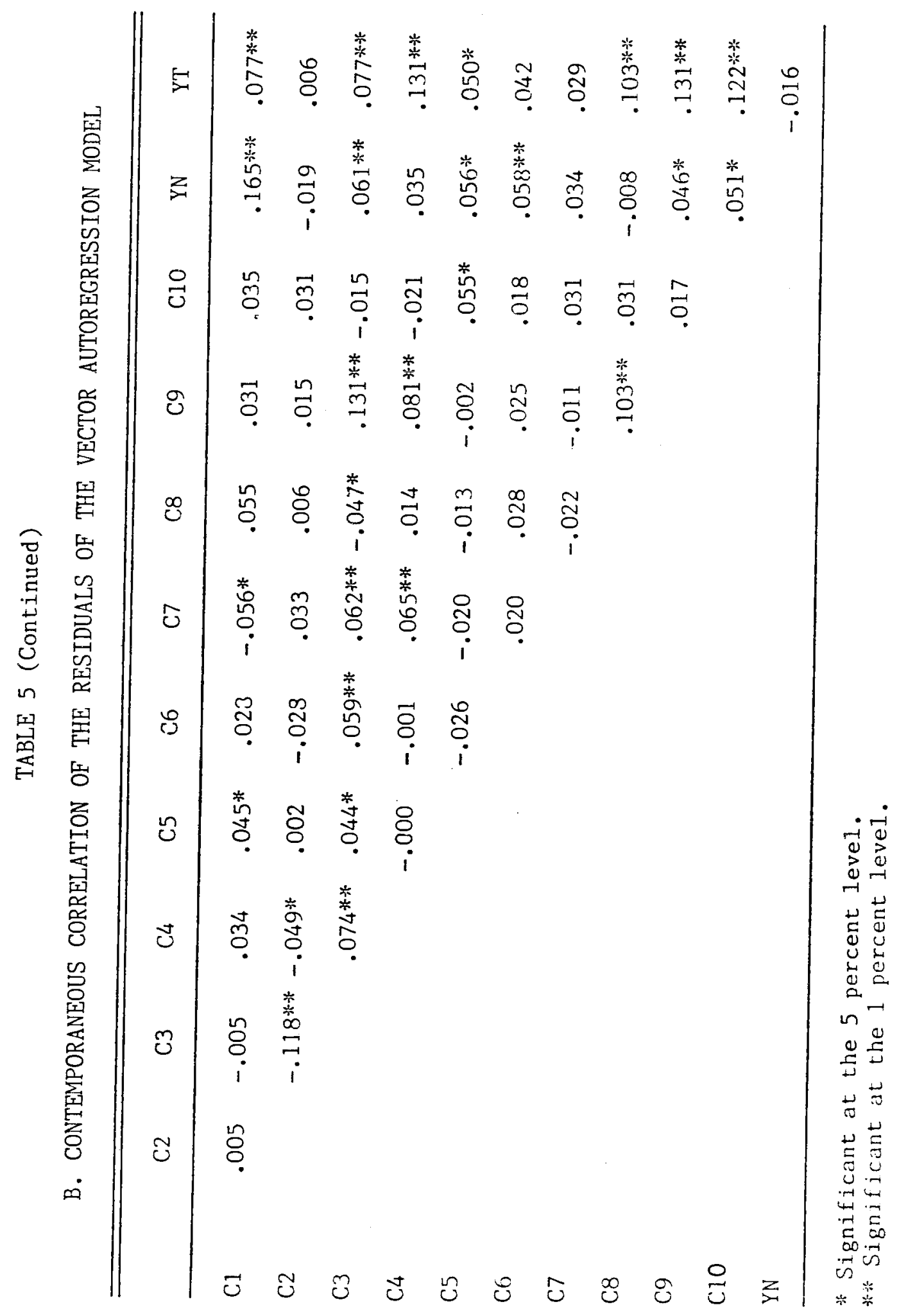


TABLE 6

CGRRELATION COEFFICIENTS OF UNEXPECTED CHANGES WITH LAGGED UNEXPECTED AND ACTUAL CHANGES

\begin{tabular}{|c|c|c|c|c|}
\hline \multirow{2}{*}{$\operatorname{Variable}(X)$} & \multicolumn{4}{|c|}{ Correlation Coefficient of $x_{4}-x_{4}^{e}$ with: } \\
\hline & $x_{3}-x_{3}^{e}$ & $x_{2}-x_{2}^{e}$ & $x_{3}-x_{2}$ & $x_{2}-x_{1}$ \\
\hline $\mathrm{C} 1$ & $-.090^{\star \star \star}$ & $-.126^{\star \star \star}$ & $-.117^{\star \star \star}$ & $-.129^{\star \star \star}$ \\
\hline $\mathrm{C} 2$ & -.019 & $-.201^{\star \star \star}$ & -.030 & $-.152^{\pi \star \star}$ \\
\hline C3 & -.038 & .004 & .007 & $-.049^{\star}$ \\
\hline C4 & $.092^{\star \star \star}$ & .004 & .043 & $-.101^{\star \star \star}$ \\
\hline $\mathrm{C5}$ & -.010 & .000 & $-.145^{\star \star \star}$ & .005 \\
\hline C6 & $-.050^{\star}$ & $-.068^{\star \star}$ & .026 & -.030 \\
\hline$C 7$ & -.019 & -.027 & $.050^{\star}$ & $-.066 \%$ \\
\hline $\mathrm{c} 8$ & $-.110^{\star \star \star}$ & -.002 & $-.094^{\star \star \star}$ & -.013 \\
\hline $\mathrm{CP}$ & $.132^{\star \star \star}$ & $.062^{\star *}$ & .034 & -.028 \\
\hline C10 & -.010 & -.005 & $-.050^{\star}$ & -.016 \\
\hline$Y N$ & $-.056^{\star}$ & $-.229^{\star \star \star}$ & $-.087^{\star \star \star}$ & $-.134^{\star \star \star}$ \\
\hline$Y T$ & $-.069^{\star \star}$ & $.095^{\star \star \star}$ & -.043 & $.095^{\star \star \star}$ \\
\hline
\end{tabular}

NOTE. -- Expenditures are family size-adjusted.

* Significant at the 5 percent level.

** Significant at the 1 percent level.

$\star \star \star$ Significant at the .1 percent level. 
TABLE 7

PARAMETR ESTIMATES FOR EQUATION $(5.7)$ WITH $\lambda=0$ A. Generalized Two-Stage Least Squares Estimates

\begin{tabular}{|c|c|c|c|c|}
\hline $\begin{array}{l}\text { Commodity } \\
\text { Group ( } j)\end{array}$ & $o_{j 1}$ & ${ }^{\rho} j 2$ & ${ }^{\rho}{ }_{j 3}$ & $R^{2}$ \\
\hline $\mathrm{C}_{1}$ & $\begin{array}{l}.275 \\
(.035)\end{array}$ & $\begin{array}{l}.249 \\
(.037)\end{array}$ & $\begin{array}{l}.099 \\
(.024)\end{array}$ & .16 \\
\hline $\mathrm{C} 2$ & $\begin{array}{l}.506 \\
(.062)\end{array}$ & $\begin{array}{l}.303 \\
(.049)\end{array}$ & $(.174)$ & .28 \\
\hline C3 & $\begin{array}{l}.963 \\
(.118)\end{array}$ & $\begin{array}{l}.944 \\
(.192)\end{array}$ & $\begin{array}{l}1.252 \\
(.328)\end{array}$ & .16 \\
\hline $\mathrm{C} 4$ & $\begin{array}{l}1.056 \\
(.055)\end{array}$ & $\begin{array}{l}1.085 \\
(.097)\end{array}$ & $\begin{array}{l}1.149 \\
(.108)\end{array}$ & .18 \\
\hline C5 & $\begin{array}{l}1.224 \\
(.374)\end{array}$ & $\begin{array}{l}1.257 \\
(.388)\end{array}$ & $\begin{array}{l}1.133 \\
(.356)\end{array}$ & .20 \\
\hline C6 & $\begin{array}{l}.617 \\
(.134)\end{array}$ & $\begin{array}{l}.613 \\
(.136)\end{array}$ & $\begin{array}{l}.530 \\
(.135)\end{array}$ & .11 \\
\hline$C 7$ & $\begin{array}{l}.867 \\
(.107)\end{array}$ & $\begin{array}{l}.632 \\
(.151)\end{array}$ & $\begin{array}{l}.361 \\
(.207)\end{array}$ & .33 \\
\hline C8 & $\begin{array}{l}.866 \\
(.111)\end{array}$ & $\begin{array}{l}.974 \\
(.212)\end{array}$ & $(.883)$ & .15 \\
\hline $\mathrm{CP}$ & $\begin{array}{l}1.041 \\
(.127)\end{array}$ & $\begin{array}{l}.911 \\
(.152)\end{array}$ & $\begin{array}{l}.962 \\
(.134)\end{array}$ & .10 \\
\hline C10 & $(.561)$ & $\begin{array}{l}.426 \\
(.086)\end{array}$ & $\begin{array}{l}.408 \\
(.077)\end{array}$ & .16 \\
\hline
\end{tabular}

NOTE. - - The instruments for lagged changes in expenditures are the associated unexpected changes. Heteroskedasticity-rubust standard errors are in parentheses. The $R^{2}$ is calculated from the second-stage regression. 
TABLE 7 (Continued)

B. Ordinary Least Squares Estimates

\begin{tabular}{|c|c|c|c|c|}
\hline $\begin{array}{l}\text { Commodity } \\
\text { Group }(j)\end{array}$ & $P_{j 1}$ & $P_{j 2}$ & $P_{j 3}$ & $R^{2}$ \\
\hline$C 1$ & $\begin{array}{l}.207 \\
(.029)\end{array}$ & $\begin{array}{l}.187 \\
(.031)\end{array}$ & $\begin{array}{l}.069 \\
(.020)\end{array}$ & .15 \\
\hline $\mathrm{C} 2$ & $\begin{array}{l}.410 \\
(.049)\end{array}$ & $(.263)$ & $(.121)$ & .34 \\
\hline C3 & $\begin{array}{l}.452 \\
(.108)\end{array}$ & $\begin{array}{l}.257 \\
(.135)\end{array}$ & $\begin{array}{l}.216 \\
(.070)\end{array}$ & .29 \\
\hline $\mathrm{C} 4$ & $\begin{array}{l}.612 \\
(.067)\end{array}$ & $\begin{array}{l}.316 \\
(.057)\end{array}$ & $\begin{array}{l}.194 \\
(.039)\end{array}$ & .33 \\
\hline $\mathrm{C5}$ & $\begin{array}{l}.670 \\
(.144)\end{array}$ & $\begin{array}{l}.374 \\
(.106)\end{array}$ & $(.231)$ & .43 \\
\hline C6 & $\begin{array}{l}.259 \\
(.064)\end{array}$ & $\begin{array}{l}.178 \\
(.050)\end{array}$ & $\begin{array}{l}.125 \\
(.034)\end{array}$ & .10 \\
\hline$C 7$ & $\begin{array}{l}.780 \\
(.054)\end{array}$ & $\begin{array}{l}.295 \\
(.096)\end{array}$ & $\begin{array}{l}.132 \\
(.061)\end{array}$ & .65 \\
\hline C8 & $\begin{array}{l}.549 \\
(.059)\end{array}$ & $\begin{array}{l}.396 \\
(.055)\end{array}$ & $\begin{array}{l}.125 \\
(.051)\end{array}$ & .34 \\
\hline $\mathrm{Cg}$ & $\begin{array}{l}.565 \\
(.103)\end{array}$ & $\begin{array}{l}.356 \\
(.097)\end{array}$ & $(.200)$ & .26 \\
\hline C10 & $\begin{array}{l}.385 \\
(.072)\end{array}$ & $\begin{array}{l}.244 \\
(.052)\end{array}$ & $\begin{array}{l}.188 \\
(.033)\end{array}$ & .26 \\
\hline
\end{tabular}

NOTE. -- Heteroskedasticity-robust standard errors are in parentheses. 
TABLE 8

WALD STATISTICS

\begin{tabular}{lcc}
\hline Commodity Group & Wald Statistic & P Value \\
\hline C1 (food) & .109 \\
C2 (rents, fuel and utilities) & 36.3 & .048 \\
C3 (cloths and household textiles) & 40.3 & .915 \\
C4 (durables) & 17.6 & .007 \\
C5 (recreation) & 48.5 & .992 \\
C6 (cultural expenses) & 12.5 & .599 \\
C7 (education) & 24.6 & .466 \\
C8 (medical expenses) & 27.0 & .702 \\
C9 (social expenses) & 22.7 & .508 \\
C10 (other) & 26.2 & .157 \\
\hline The degreees of freedom is 27. & 34.4 & \\
\hline
\end{tabular}


TABLE 9

PARAMETR ESTIMATES FOR EQUATION (5.7)

BY GENERALIZED TWO-SRAGE LEAST SQUARES

\begin{tabular}{|c|c|c|c|c|}
\hline $\begin{array}{l}\text { Comodity } \\
\text { Group }(j)\end{array}$ & $\rho_{j 1}$ & ${ }^{\rho} j 2$ & $P_{j 3}$ & $\alpha_{j}$ \\
\hline C1. & $\begin{array}{l}.310 \\
(.042)\end{array}$ & $\begin{array}{l}.277 \\
(.041)\end{array}$ & $\begin{array}{l}.106 \\
(.026)\end{array}$ & $(.110)$ \\
\hline $\mathrm{C} 2$ & $(.572)$ & $\begin{array}{l}.343 \\
(.058)\end{array}$ & $\begin{array}{l}.196 \\
(.041)\end{array}$ & $(.012)$ \\
\hline C3 & $\begin{array}{l}1.084 \\
(.145)\end{array}$ & $\begin{array}{l}1.064 \\
(.226)\end{array}$ & $\begin{array}{l}1.415 \\
(.385)\end{array}$ & $\begin{array}{l}-.158 \\
(.136)\end{array}$ \\
\hline $\mathrm{CA}$ & $\begin{array}{l}1.190 \\
(.085)\end{array}$ & $\begin{array}{l}1.224 \\
(.122)\end{array}$ & $\begin{array}{l}1.297 \\
(.141)\end{array}$ & $(.440)$ \\
\hline$C 5$ & $\begin{array}{l}1.370 \\
(.417)\end{array}$ & $\begin{array}{l}1.376 \\
(.431)\end{array}$ & $\begin{array}{l}1.297 \\
(.395)\end{array}$ & $\begin{array}{l}.228 \\
(.149)\end{array}$ \\
\hline C6 & $\begin{array}{l}.697 \\
(.157)\end{array}$ & $\begin{array}{l}.693 \\
(.160)\end{array}$ & $\begin{array}{l}.599 \\
(.157)\end{array}$ & $\begin{array}{l}.004 \\
(.018)\end{array}$ \\
\hline$C 7$ & $\begin{array}{l}.981 \\
(.134)\end{array}$ & $\begin{array}{l}.713 \\
(.178)\end{array}$ & $\begin{array}{l}.410 \\
(.235)\end{array}$ & $\begin{array}{l}.087 \\
(.071)\end{array}$ \\
\hline C8 & $\begin{array}{l}.968 \\
(.133)\end{array}$ & $\begin{array}{l}1.087 \\
(.241)\end{array}$ & $\begin{array}{l}.997 \\
(.254)\end{array}$ & $\begin{array}{l}.079 \\
(.061)\end{array}$ \\
\hline $\mathrm{C9}$ & $\begin{array}{l}1.177 \\
(.159)\end{array}$ & $\begin{array}{l}1.035 \\
(.183)\end{array}$ & $\begin{array}{l}1.094 \\
(.164)\end{array}$ & $\begin{array}{l}.133 \\
.104\end{array}$ \\
\hline C10 & $(.633)$ & $\begin{array}{l}.481 \\
(.100)\end{array}$ & $(.460)$ & $\begin{array}{l}.067 \\
(.065)\end{array}$ \\
\hline$\hat{\lambda}=$ & sum of EDY $j 4$ & coefficients over & $j=(.116)$ & \\
\hline
\end{tabular}

NOTE. -- Heteroskedasticity-robust standard errors are in parentheses. 
TABLE 10

CORRELATION OF FAMILY SIZE-ADJUSTED EXPECTED CHANGE IN DISPOSABLE INCOME WITH LAGGED EXPENDITURES CHAGES

Commodity

Group ( $j$ )

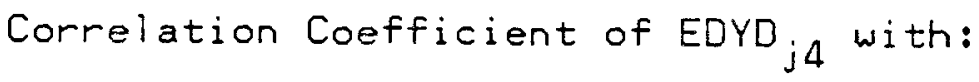

$$
x_{j 2^{-x}} j 1 \quad x_{j 3^{-x_{2}}} \quad x_{j 4^{-x_{j 3}}}
$$

$-.025$

$-.027$

.016

$-.016$

.028

$-.029$

.036

$-.023$

$-.013$

.011

$.053^{\star}$

$-.025$

$-.043$

.035

$-.079^{\star \star \star}$

$.054^{\star}$

C10

NOTE. - EDY j4 $(j=1,2, \ldots, 10)$ is family size-adjusted expected
disposable income change and is defined formally in $(3,16)$.

* Significant at the 5 percent level.

* Significant at the 1 percent level.

$\star * \star$ Significant at the .1 percent level. 
AGGREGATE TIME-SERIES ESTIMATE OF THIRD-ORDER AUTOREGRESSIONS ON EXPENDI TURES CHANGES

Commodity Group in the National Income Acounts $\rho_{1}$

$P_{2}$
Food, beverages and tobacco

.245

$(.161)$

.210

$(.164)$

.032

Rents, fuel and utilities ${ }^{\dagger}$

Clothes and footwares

Durables

Recreation and education

Medical care

$\begin{array}{lll}.313 & .443 \\ (.151) & (.140) & (.377 \\ (.146)\end{array}$

$\begin{array}{lll}.390 & .306 & .054 \\ .169) & (.177) & (.171)\end{array}$

$$
-.033
$$

(.161)

.171

$(.158)$

.030

$(.163)$

$\begin{array}{lll}.177 & .396 \\ .146) & (.140) & (.061 \\ & .149)\end{array}$

.438
$(.155)$

.246
$(.166)$

.161

$(.157)$

NOTE. - - Standard errors are in parentheses. The estimated modei is $x_{t}=$ seasonal dummies $-\rho_{1} x_{t-1}-\rho_{2} x_{t-2}-\rho_{3} x_{t-3}$, where $x_{t}$ is expenditures change from quarter $t-1$ to quarter $t$. The data on expenditures are in real and per capita terms. The sample period is $1971: \mathrm{Q} 1$ - $1982: \mathrm{Q} 2$.

† Rents here include imputed rents. 
TABLE 12

PARAMETR ESTIMATES FOR EQUATION (6.3)

BY GENERALIZED TWO-SRAGE LEAST SQUARES

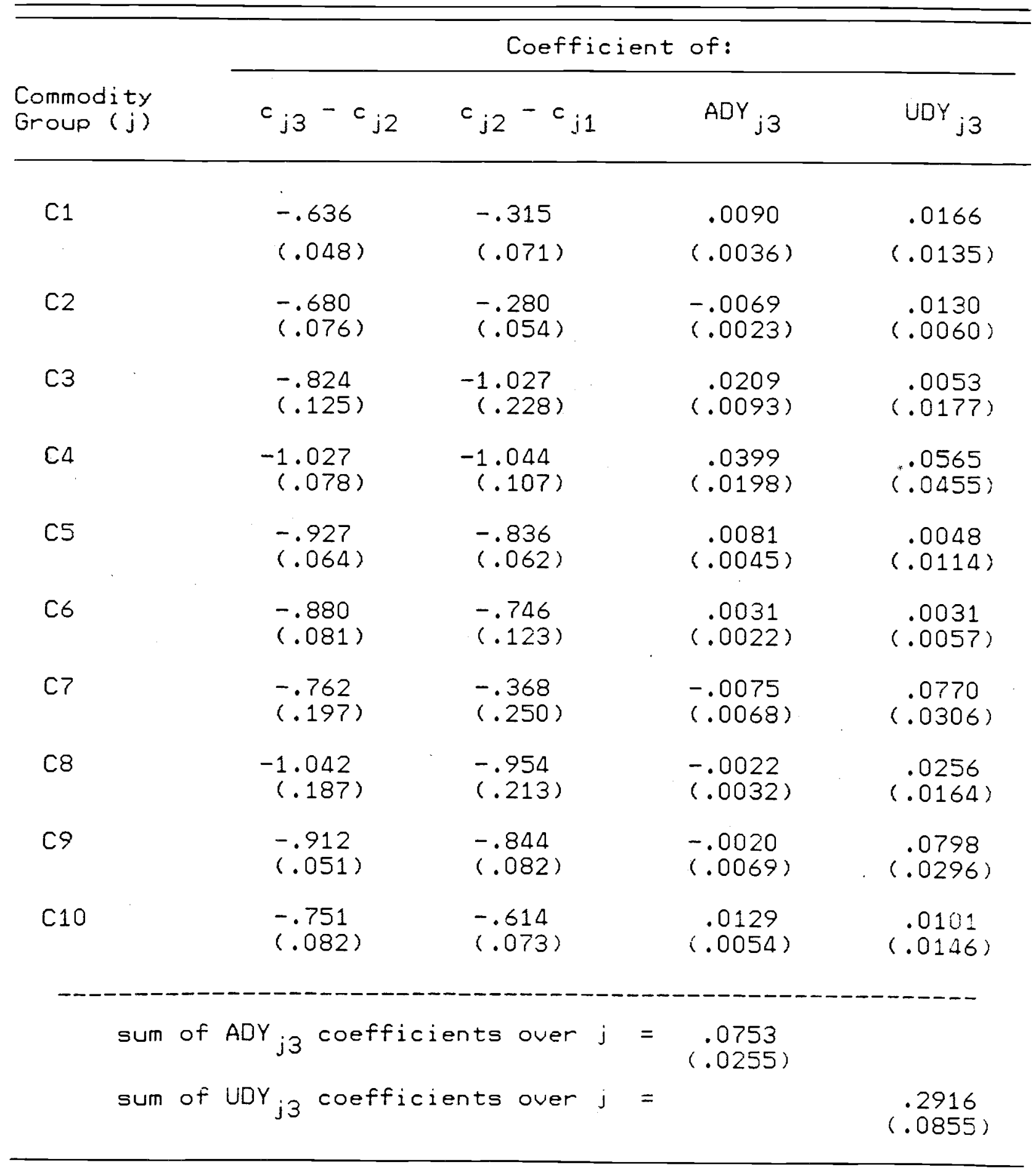

NOTE. -- Heteroskedasticity-robust standard errors are in parentheses. The instruments for lagged expenditures changes are their associated unexpected changes. See equations (6.2) and (6.4) in the text for the derinition of $A D Y_{j 3}$ and UDY $j 3^{\circ}$ 